\title{
Colossendeis species (Pycnogonida: Colossendeidae) collected during the Italica XIX cruise to Victoria Land (Antarctica), with remarks on some taxonomic characters of the ovigers
}

\author{
ESPERANZA CANO and PABLO J. LÓPEZ-GONZÁLEZ
}

Biodiversidad y Ecología de Invertebrados Marinos, Departamento de Fisiología y Zoología, Facultad de Biología, Universidad de Sevilla, Apdo. 1095, 41080-Sevilla, Spain. E-mail: ecano@us.es

\begin{abstract}
SUMMARY: The pycnogonid fauna of the genus Colossendeis collected during the Italica XIX cruise to Victoria Land (Ross Sea, Antarctica) was studied. A total of 19 specimens of six species were collected: Colossendeis australis (6), $C$. wilsoni (3), C. scotti (2), C. robusta (3), C. lilliei (2) and C. megalonyx (3). In the present contribution the observed variability of all collected Colossendeis species is described and illustrated. The previously synonymised $C$. lilliei is considered a different species from $C$. robusta. The observations made in this study lead us to discuss a controversy about the total number of oviger segments in this genus. Despite the currently established 10-segmented status, a short basal element is here considered to be a possible $11^{\text {th }}$ segment. A detailed SEM study of the last oviger segment is carried out in all collected species, showing some intraspecific and the interspecific variability in the structures examined (shape and number of rows of compound spines, morphology of terminal claw, etc.). Finally, we discuss the taxonomic value of these characters of the last strigilis segment for distinguishing the Colossendeis species, and their possible utility in establishing internal phylogenetic relationships in future contributions.
\end{abstract}

Key words: Pycnogonida, Colossendeidae, Colossendeis, SEM characters, benthic fauna, Antarctica.

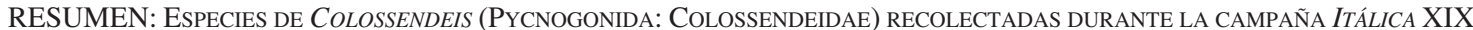
A TiERRA Victoria (ANTÁRTIDA), CON OBSERVACIONES SOBRE ALgUNOS CARACTERES TAXONÓMICOS DEL OVÍGERO. - En este trabajo se estudia la fauna de picnogónidos pertenecientes al género Colossendeis recogidos en la campaña Italica XIX, realizada en la costa de Tierra Victoria (mar de Ross, Antártida). En total se capturaron 19 ejemplares, pertenecientes a seis especies: Colossendeis australis (6), C. wilsoni (3), C. scotti (2), C. robusta (3), C. lilliei (2) y C. megalonyx (3). En el presente trabajo se describe e ilustra la variabilidad morfológica observada en cada una de ellas. Se considera $C$. lilliei como especie distinta de $C$. robusta, previamente sinonimizadas. Las observaciones llevadas a cabo en este estudio nos permiten abordar la controversia sobre el número total de segmentos del ovígero en este género. A pesar del estado 10-segmentado actualmente considerado, la presencias de un corto elemento basal no hace considerar la posibilidad de un onceavo segmento. Se realiza un estudio detallado del último segmento del ovígero al MEB de todas las especies capturadas, se muestra la variabilidad intraespecífica observada, y por otro lado la variabilidad en las estructuras (forma y número de líneas de las espinas compuestas, morfología del garfio terminal, etc.) entre las especies estudiadas. Finalmente, discutimos el valor taxonómico de estos caracteres provenientes del último segmento del strigilis para separar las especies de este género, y su posible utilidad para establecer relaciones filogenéticas internas en futuros estudios.

Palabras clave: Pycnogonida, Colossendeidae, Colossendeis, caracteres MEB, fauna bentónica, Antártida.

\section{INTRODUCTION}

Pycnogonids are an important component of Antarctic and sub-Antarctic benthos, especially from the point of view of species richness. Although the pycnogonid fauna of Antarctic and subAntarctic waters has been the subject of much research [the most recent and relevant reports on 


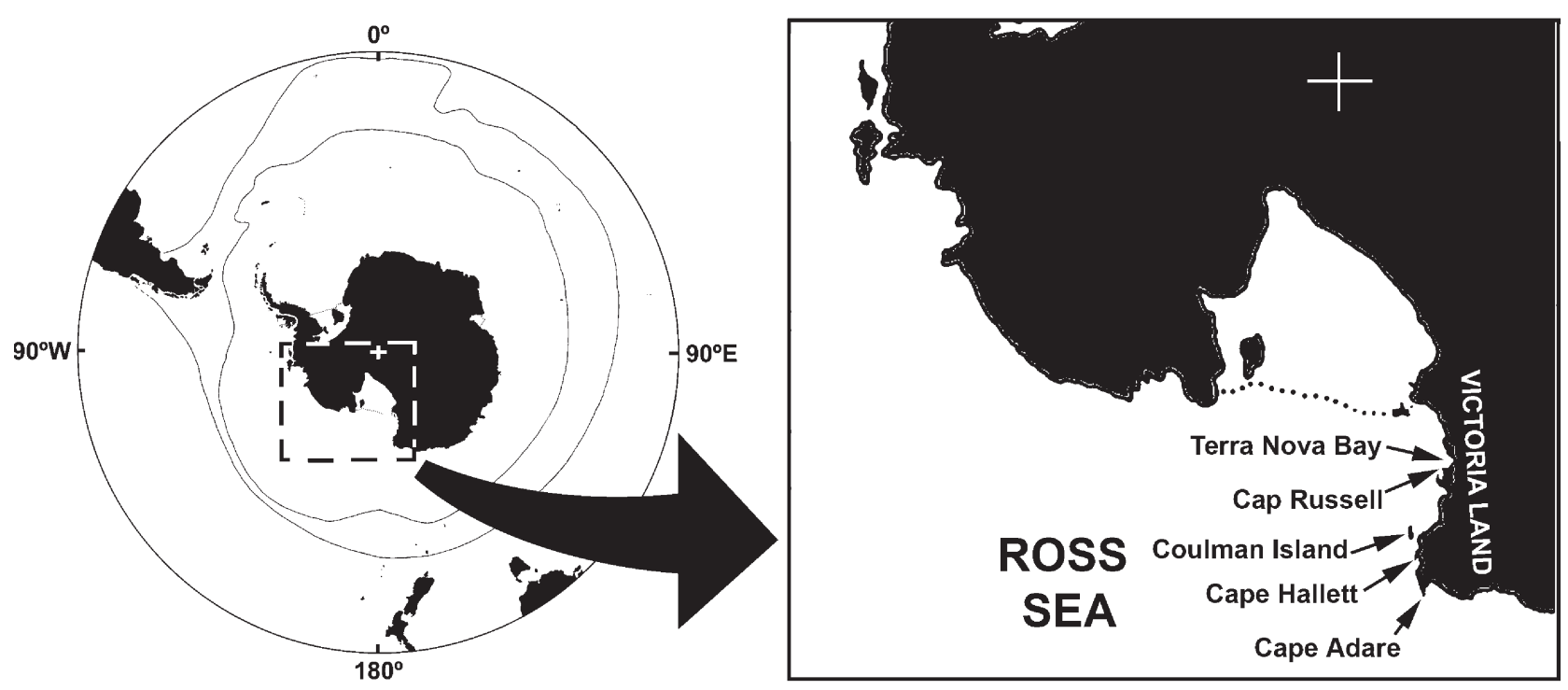

FIG. 1. - Localities where Colossendeis species were collected. Coordinates and other sampling data are in the text.

Antarctic and sub-Antarctic fauna are those of Fry and Hedgpeth (1969), Turpaeva (1974), Munilla (1991), Pushkin (1993), Child (1994a, b; 1995a, b, c), and Chimenz and Gravina (2001)] the descriptions of many of the species have been based on a small number of specimens.

The Antarctic and sub-Antarctic seas encompass an extraordinary number of Colossendeis species: at least 30 , most of which are endemic to the Southern Ocean. In several cases, the specific limits are not clear, mainly because of the lack of information about character variability, and about their true taxonomic value. Some keys have been proposed to help in the initial identification of Colossendeis species (Calman, 1915; Gordon, 1932, 1938; Fry and Hedgpeth, 1969; Child, 1995b). However, owing to a lack of information about the variability of some characters, these tools may become unreliable when new information from new collections or redescriptions are available.

During the 2004 Victoria Land Transect cruise (Italica cruise XIX, 3 February to 4 March, 2004), the benthic fauna from Terra Nova Bay to Cape Adare, between 100 and 500 metres in depth, was intensively sampled. In this paper, data regarding the Colossendeis species collected in the course of the Victoria Land Transect cruise are presented. Each Colossendeis species is described, including (when necessary) illustrations and variations between adult and juvenile specimens. The variability observed in some characters when compared to previously published literature is briefly discussed.
Finally, the taxonomic utility of the compound spines and terminal claw on the last oviger segment is explored through an SEM study.

\section{MATERIAL AND METHODS}

The material was collected off the Victoria Land coast (VTL, Ross Sea, Antarctica) (Fig. 1) with the aid of a small Agassiz trawl. The specimens were sorted, fixed in $10 \%$ buffered formalin in seawater and then transferred to $70 \%$ ethanol. The terminal segment of the right oviger of at least two specimens per species was prepared for SEM study, dehydrated in an alcoholic series from 70 to $100 \%$, subsequently criticalpoint-dried, mounted on stubs, coated with gold-palladium and observed with a Philips XL30 SEM.

The material here studied has been deposited in the Museo Nazionalle dell'Antartide, in Genova (MNA), and in the collection of the "Biodiversidad y Ecología de invertebrados Marinos" research group of the Faculty of Biology at the University of Seville, Spain (BEIM).

The literature used for the identification of the Colossendeis species collected during the VTL cruise mainly includes the most important work carried out in the last century on Antarctic pycnogonid fauna: Calman (1915), Gordon (1932, 1938, 1944), Fry and Hedgpeth (1965), and Child (1995b). Additional literature for each Colossendeis species is referenced in the remarks sections after the description of the material examined for this study. 


\section{RESULTS}

\section{Description of the species}

Family ColossendeIDAE Hoek, 1881

Genus Colossendeis Jarzynsky, 1870

Colossendeis megalonyx Hoek, 1881

(Figs. 2-3)

Material examined. MNA (1078), Italica XIX cruise, Cape Hallett, Victoria Land, Ross Sea, Antarctica, $72^{\circ} 17.4^{\prime}$ S $170^{\circ} 26.4^{\prime} \mathrm{E}, 17 \mathrm{Feb}$ 2004, Agassiz trawl, 205-258 m depth, one male and one female. BEIM (CRP-7), Italica XIX cruise, Cape Hallett, Victoria Land, Ross Sea, Antarctica, 72 ${ }^{\circ} 16.9^{\prime} \mathrm{S}$ 170 $12.2^{\prime} \mathrm{E}, 10$ Feb 2004 , Rauschert dredge, $391 \mathrm{~m}$ depth, one male (?).
Description. Size moderate for the genus, up to $125 \mathrm{~mm}$ leg span in the examined material.

Proboscis cylindrical and truncated distally, smooth, nearly straight, distal two-third slightly inflated, 1.8 to 1.9 times the length of trunk.

Trunk without segmental suture-line traces, with lateral processes well separated, at least half of processes diameter; dorsal surface and processes smooth.

Abdomen erect, without setules.

Ocular tubercle as a tall cone, distinct four eyes, anterior pair larger and slightly more apical than posterior one.

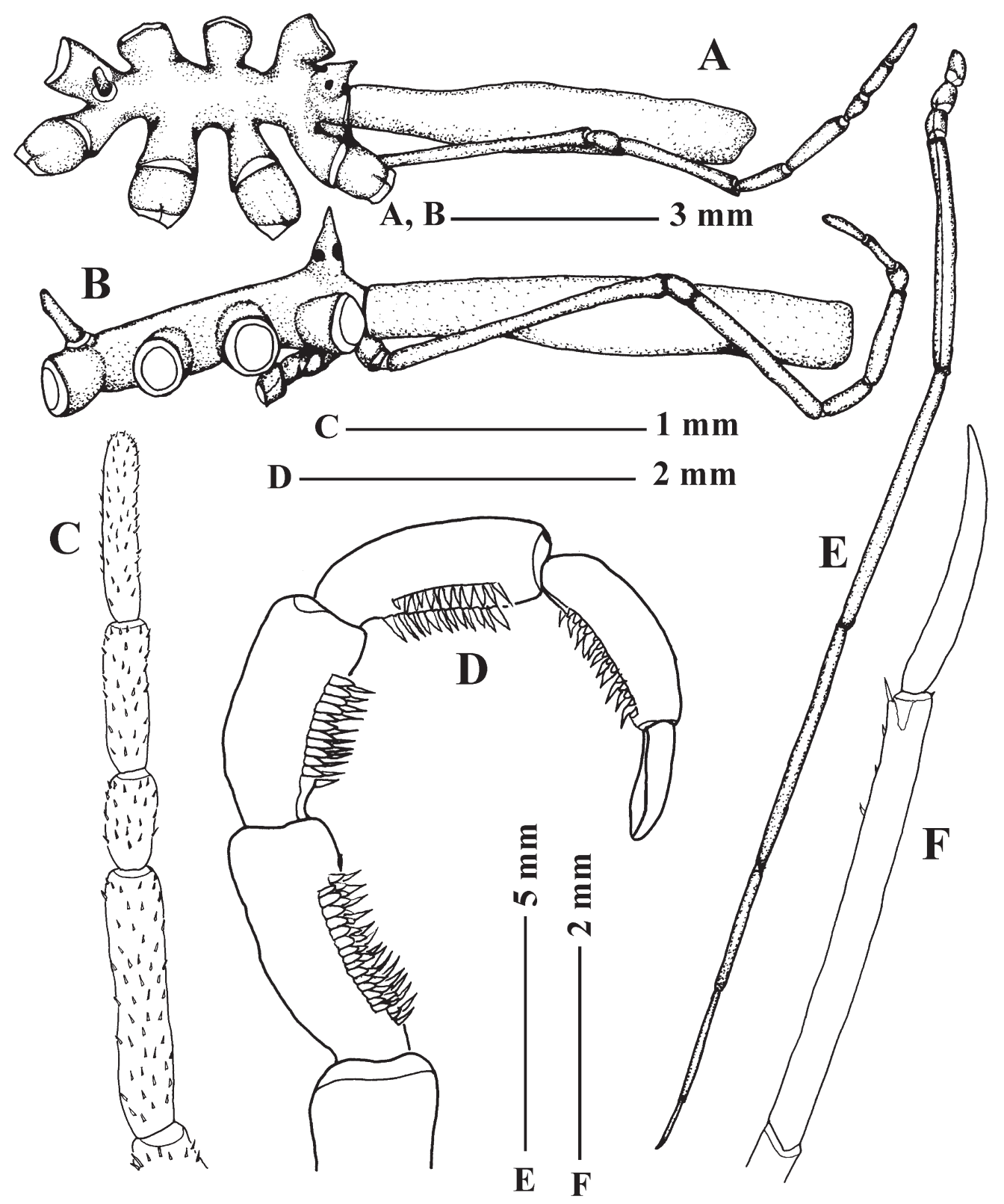

FIG. 2. - Colossendeis megalonyx Hoek, 1881. (MNA: 1078): A, dorsal view of body; B, lateral view of body; C, distal segments of palp; D, strigilis; $\mathrm{E}$, third leg of right side; $\mathrm{F}$, distal leg segments. 


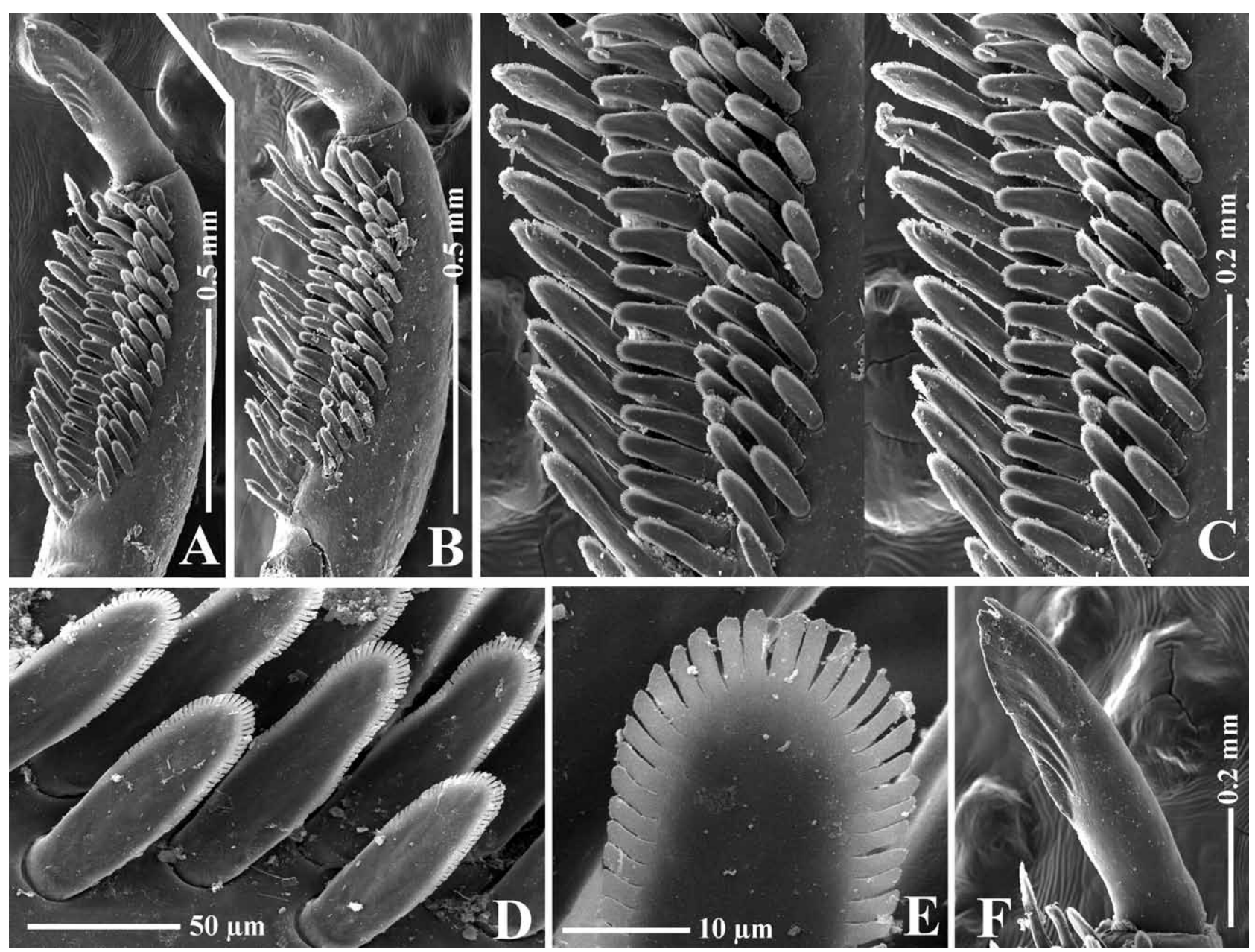

FIG. 3. - Colossendeis megalonyx Hoek, 1881. SEM photographs: A-B, terminal oviger segment (MNA: 1078, BEIM: CRP-7, respectively); $\mathrm{C}$, detail from A, showing rows of compound spines, stereo pair; D, detail from C, showing a set of compound spines; E, distal part of a com pound spine showing pectinate border; $\mathrm{F}$, detail from A, showing spatulate terminal claw.

Palps 10-segmented, slender, longer than proboscis, with scarcely distributed short setae, except for the last five segments that are more setose. Seventh segment longer than any of the three distal ones, about 1.5 times length of sixth. Eight segment shorter than any of the two distal ones. Tenth segment slightly longer than ninth (1.1-1.2 times, range observed on three specimens).

Ovigers 10-segmented and conventional, strigilis well developed, terminal segment with 6 rows of compound spines, elongated, flat, with pectinate borders (see Fig. 3). Minute setae scarcely distributed on the surface of the segments. Terminal claw spatulate, slightly curved, 0.5-0.6 times the length of the distal segment.

Legs slender, minute setae scarcely distributed on the surface of the segments. Femur and both tibia subequal. Tarsus about 1.3 propodus length. Propodus with few ventral spines distally. Claw slightly curved, about 0.55 (based on two speci- mens, range 0.48 to 0.62 ) of the propodal length.

Measurements (in mm), based on the larger specimen in the collection MNA (1078). Length of trunk (tip of cephalic segment to tip of fourth lateral processes): 6.5. Width of trunk across first lateral processes: 3.5. Length of proboscis: 11.5 . Length of abdomen: 1.4. Length of palp: 17.9; articles of palp length (1 to 10): 0.5-0.3-6.1-0.8-4-1.2-1.8-0.6-1.21.4. Length of third leg: 56.2; articles of leg 3 length: coxa 1 (1.5), coxa 2 (1.1), coxa $3(1.1)$, femur (13), tibia 1 (13), tibia 2 (12), tarsus (6.4), propodus (5), claw (3.1). Length of oviger: 24.4; articles of oviger length ( $1^{\text {st }}$ to $\left.10^{\text {th }}\right)$ : $0.5-0.3-0.4-7.8$ 2.8-6.9-1.5-1.1-1-1, ovigeral claw 0.6.

Geographical and bathymetric distribution. According to Child (1995b), this species with its possible subspecies has a wide bathymetric range (7-4900 $\mathrm{m}$ in depth), and has been reported from 
sub-Antarctic and Antarctic waters, as well as the southern areas of islands and continents surrounding the Southern Ocean (South Africa, Madagascar, New Zealand and South America).

Remarks. According to Child (1995b), the taxonomic status of Colossendeis megalonyx, considered as a single variable species or the set of subspecies proposed by Fry and Hedgpeth (1969), is far from being solved. The first author, examining a large number of specimens, could not find a reliable set of useful characters to separate his material with certainty into the subspecies described in the literature. Only C. scoresbii Gordon, 1932, included as a subspecies by Fry and Hedgpeth, is recognised as a separate species, based on the study of additional specimens (see Fry and Hedgpeth, 1969: 32). In the present contribution, the few specimens collected in Victoria Land do not permit additional discussion or remarks on the validity of subspecies. One of the supposed characters for $C$. megalonyx is the "proboscis much longer than trunk" (see Child, 1995b: 72 , in key). However, according to the original description of C. orcadense (see Hodgson, 1908)one of the proposed subspecies of $C$. megalonyxthe proboscis/trunk ratio is 1.1 . This last feature made material attributed to this species unidentifiable according to Child's key. Furthermore, the characters used by Fry and Hedgpeth to separate the subspecies could also be used at specific levelindeed they are among the features used by Child (1995b: 90) to differentiate his newly collected material of $C$. scoresbii.

We agree with Child concerning the need to explore new sources of characters which can be used to decide how many species or subspecies can be considered to be in this complex. Molecular data could be one these sources, although, as will be discussed below, other microscopic morphological characters could also be used. Under an SEM study the last oviger segment shows a number of characters that could now be explored in more detail than in previous contributions based on optical microscopy (Hoek, 1881; Hodgson, 1907; Fry and Hedgpeth, 1969).

\section{Colossendeis glacialis Hodgson, 1907} (Figs. 4-5)

Material examined. MNA (1079), Italica XIX cruise, Cape Russell, Victoria Land, Ross Sea, Antarctica, $74^{\circ} 50.2^{\prime} \mathrm{S} 164^{\circ} 05.5^{\prime} \mathrm{E}, 22 \mathrm{Feb}$ 2004, Agassiz trawl, $216 \mathrm{~m}$ depth, one male. BEIM (CRP-9), Italica
XIX cruise, Cape Hallett, Victoria Land, Ross Sea, Antarctica, $72^{\circ} 17.1^{\prime} \mathrm{S} 170^{\circ} 14.0^{\prime} \mathrm{E}, 16 \mathrm{Feb} 2004$, Rauschert dredge, 316-328 m depth, one male. BEIM (CRP-8), Italica XIX cruise, Cape Adare, Victoria Land, Ross Sea, Antarctica, $71^{\circ} 15.5^{\prime} \mathrm{S} 170^{\circ} 41.9^{\prime} \mathrm{E}, 15 \mathrm{Feb}$ 2004, Agassiz trawl, 119-120 m depth, one male.

Description. Size moderate for the genus, up to $115 \mathrm{~mm}$ leg span in the examined material.

Proboscis cylindrical and rounded distally, with minute setae irregularly distributed, inclined downwards, slightly inflated at mid length and distal part, subequal to trunk in length.

Trunk without intersegmental suture-line traces, with lateral processes well separated, at least half of process diameter; dorsal surface and processes with minute setae irregularly distributed.

Abdomen of variable position in the examined material (erect in one of the specimens, and pointing downwards in the other one), with minute setae irregularly distributed.

Ocular tubercle as a tall and broad cone, four distinct eyes, anterior pair larger and slightly more apical than posterior pair.

Palps 10-segmented, slender, longer than proboscis, with many short sharp setae. Seventh segment larger than any of the three distal ones, about 1.3 times length of sixth. Eight, ninth and tenth segments subequal.

Ovigers 10-segmented and conventional, strigilis well developed, terminal segment with 4 rows of compound spines, elongated and flat, with pectinate borders, larger spines (posterior row) with marked concave to spoon-shaped distal part (see Fig. 5). Terminal claw narrowing to a blunt point, with wide base, about 0.4 times the length of the distal segment.

Legs slender, femur and tibia 1 subequal, tibia 2 slightly shorter, segment covered by minute setae. Three distal segments with a distinct ventral row of spines. Tarsus 1.3-1.6 propodus length. Claw slight curved, about 0.4 times propodal length (based on two specimens).

Measurements (in mm), based on the larger specimen in the collection MNA (1079). Length of trunk (tip of cephalic segment to tip of fourth lateral processes): 7.9. Width of trunk across first lateral processes: 4.2. Length of proboscis: 7.5. Length of abdomen: 2.1. Length of palp: 12; articles of palp length (1 to 10): 0.6-0.4-3.1-0.4-2.3-1-1.3-0.9-1.10.9 . Length of third leg: 54.6 ; articles of leg 3 length: coxa 1 (1.4), coxa 2 (1.4), coxa 3 (1.3), femur (14), tibia 1 (15), tibia 2 (11), tarsus (5.6), propodus (3.5), claw (1.4). Length of oviger: 38.3; 


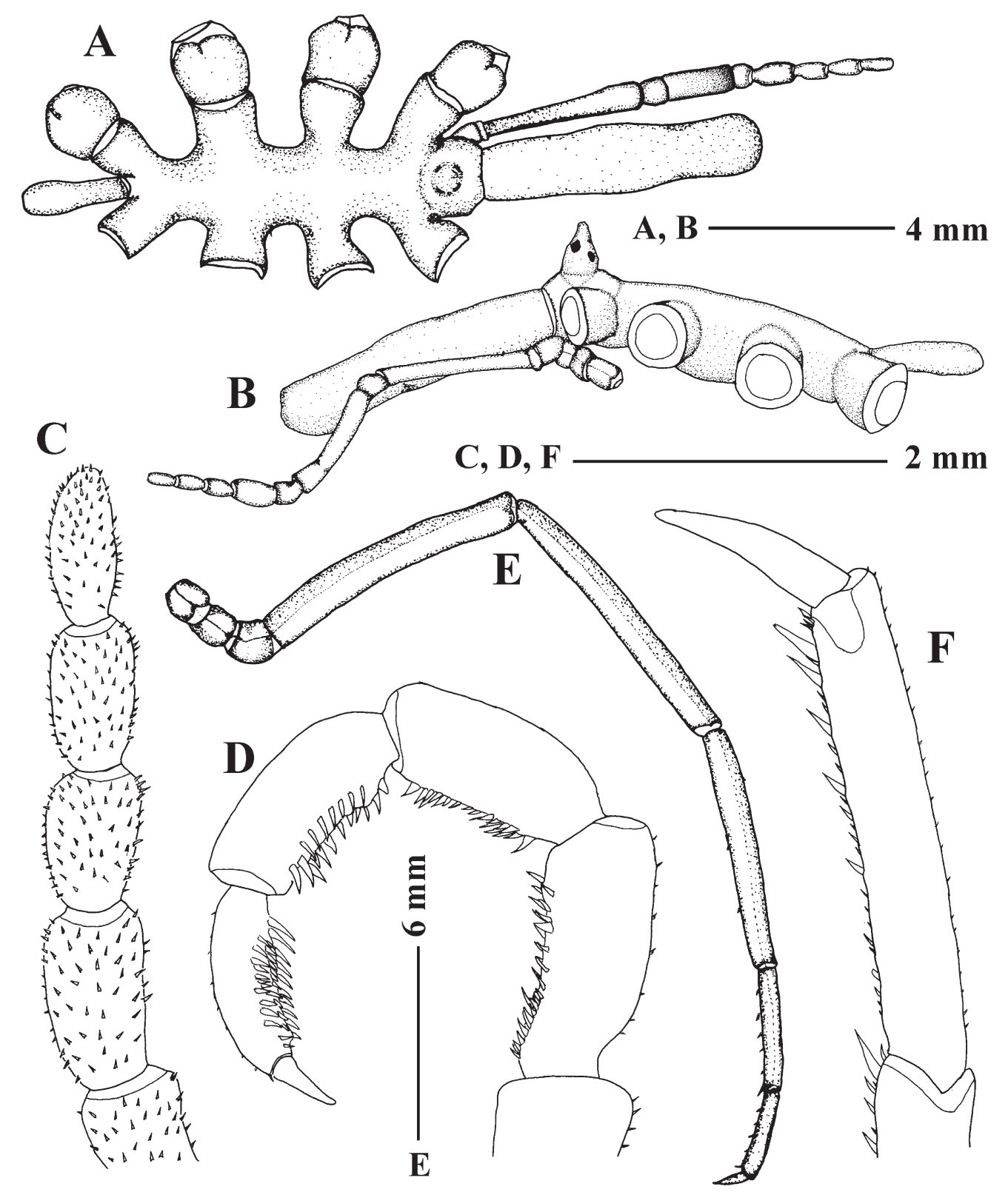

FIG. 4. - Colossendeis glacialis Hoek, 1881. (BEIM: CRP-9): A, dorsal view of body; B, lateral view of body; C, distal segments of palp; D, strigilis; E, third leg of right side; F, distal leg segments.

articles of oviger length ( $1^{\text {st }}$ to $\left.10^{\text {th }}\right)$ : $0.5-0.5-0.7$ 7.1-1.7-6.7-1.6-1.3-1.4-1.2, ovigeral claw 0.5 .

Geographical and bathymetric distribution. Colossendeis glacialis has been reported from Antarctic and sub-Antarctic areas, with a circumpolar distribution, from shallow waters up to more than $500 \mathrm{~m}$ in depth (Hodgson, 1907; Calman, 1915; Stiboy-Risch, 1993).

Remarks. In the last review of Antarctic and subAntarctic Colossendeidae, Child (1995b) considered three species (Colossendeis glacialis Hodgson,
1907, C. gracilipes Bouvier, 1913, and C. lilliei Calman, 1915) as junior synonyms of $C$. robusta Hoek, 1881, based on possible intraspecific variability of distinctive characters such as separation of the lateral processes and relation between the length of the femur and the second tibia (see also Hodgson, 1907, Fry and Hedgpeth, 1969). In the case of $C$. gracilipes, Calman (1915) pointed out its similarity to $C$. glacialis, noting that they only differ in the narrowing aspect of the proboscis base, and a relatively larger terminal segment of the palp in comparison with the preceding one. Taking into account 


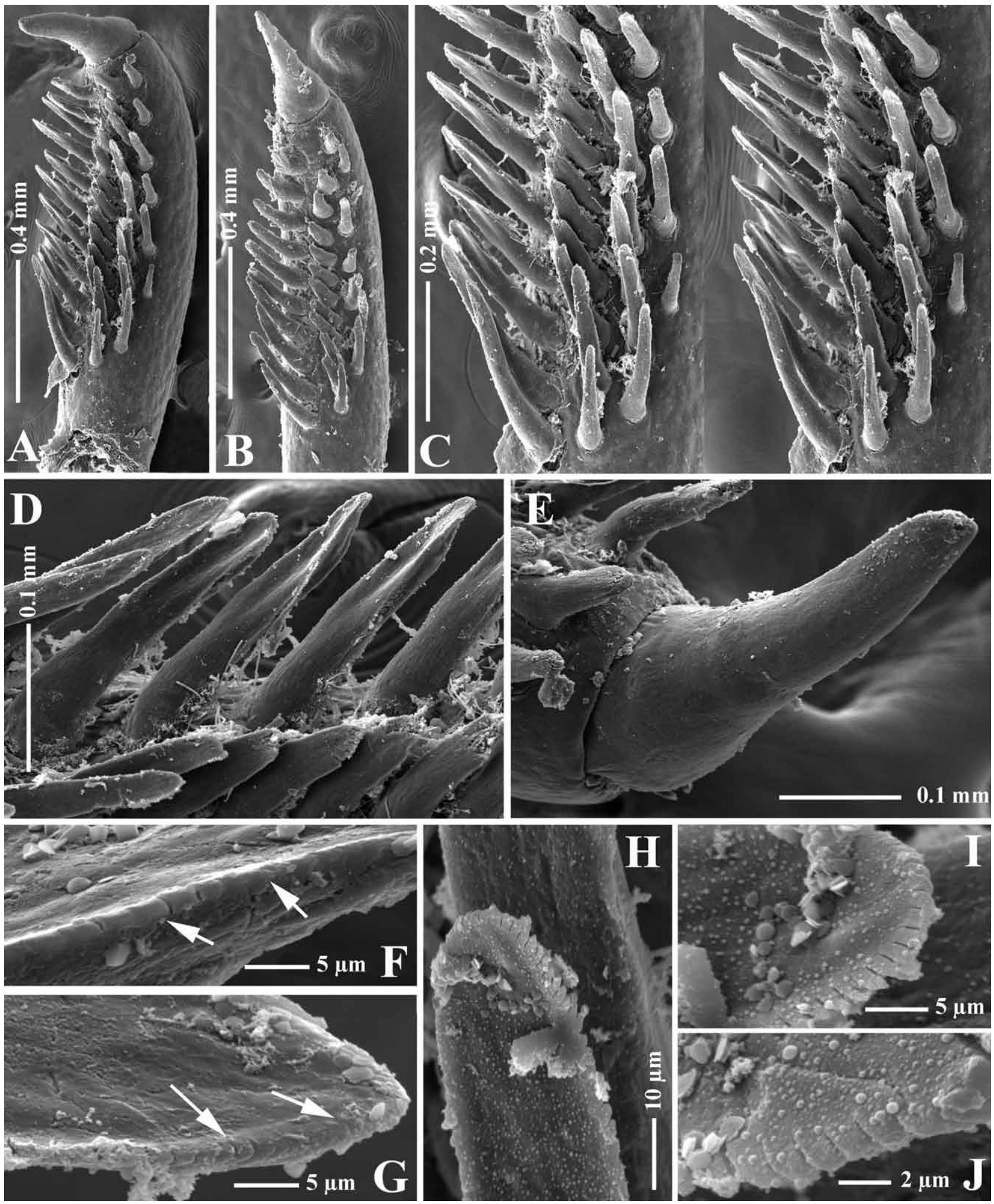

FIG. 5. - Colossendeis glacialis Hoek, 1881. SEM photographs: A-B, terminal oviger segment (MNA: 1079, BEIM: CRP-9, respectively); C, detail from A, showing rows of compound spines, stereo pair; D, detail from C, showing a set of compound spines; E, detail from A, showing terminal claw; F-G, detail from D, larger compound spines showing eroded borders with traces of previous pectinate state (white arrows); H-J, detail from D, medium size compound spines, showing borders clearly pectinate.

that Bouvier's notes were taken on only two specimens, it is difficult to be certain of the true variabil- ity of the relation between the two distal palp segments. 
In the material here identified as Colossendeis glacialis, the relation in length among the femur, first tibia, and second tibia in the present material agrees with previous data for both $C$. glacialis (see Hodgson, 1907: 62, Stiboy-Risch, 1993: 254) and $C$. gracilipes (see Bouvier, 1913: 61), in which the femur is slightly shorter than the first tibia, and the second tibia is about $3 / 4$ of the first. According to Calman (1915), C. gracilipes is probably a junior synonym of $C$. glacialis.

Stiboy-Risch (1993) recently redescribed the types of Colossendeis glacialis, and C.robusta. Our material clearly supports the idea that $C$. glacialis differs from C. robusta and C. acuta Stiboy-Risch,
1993, in the relative proportion of distal palp segments, femur, first and second tibiae, and distal claw and propodus, disagreeing with Child's synonyms C. glacialis and C. robusta.

\section{Colossendeis australis Hodgson, 1907}

(Figs. 6-7)

Material examined. MNA (1080), Italica XIX cruise, off Terra Nova Bay, Victoria Land, Ross Sea, Antarctica, $74^{\circ} 43.2^{\prime} \mathrm{S}$ $164^{\circ} 13.1^{\prime} \mathrm{E}, 20$ Feb 2004, Agassiz trawl, 362-366 m depth, 2 juvenile specimens. BEIM (CRP-11), Italica XIX cruise, Cape Hallett, Victoria Land, Ross Sea, Antarctica, $72^{\circ} 18.5^{\prime}$ 'S $170^{\circ} 26.8^{\prime} \mathrm{E}, 14 \mathrm{Feb}$ 2004, Agassiz trawl, 234-235 m depth, two males. MNA (1081), Italica XIX cruise, Cape Adare, Victoria Land, Ross Sea, Antarctica, $71^{\circ} 17.1^{\prime} \mathrm{S} 170^{\circ} 38.4^{\prime} \mathrm{E}, 14 \mathrm{Feb} 2004$, Agassiz trawl, 416-421 m depth, one male. BEIM (CRP-10), Italica XIX cruise,

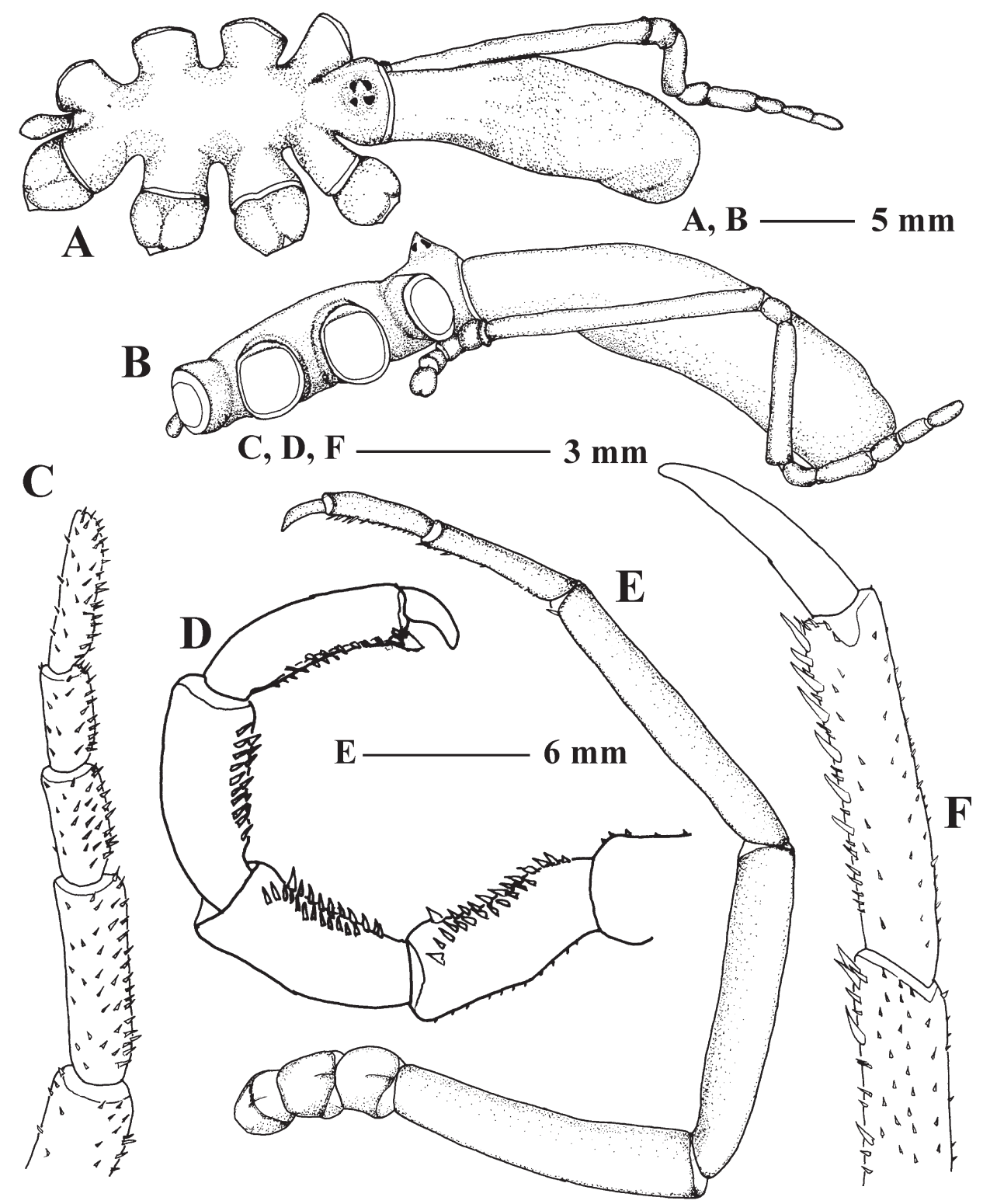

FIG. 6. - Colossendeis australis Hodgson, 1907. (BEIM: CRP-11): A, dorsal view of body; B, lateral view of body; C, distal segments of palp; D, strigilis; E, third leg of right side; F, distal leg segments. 

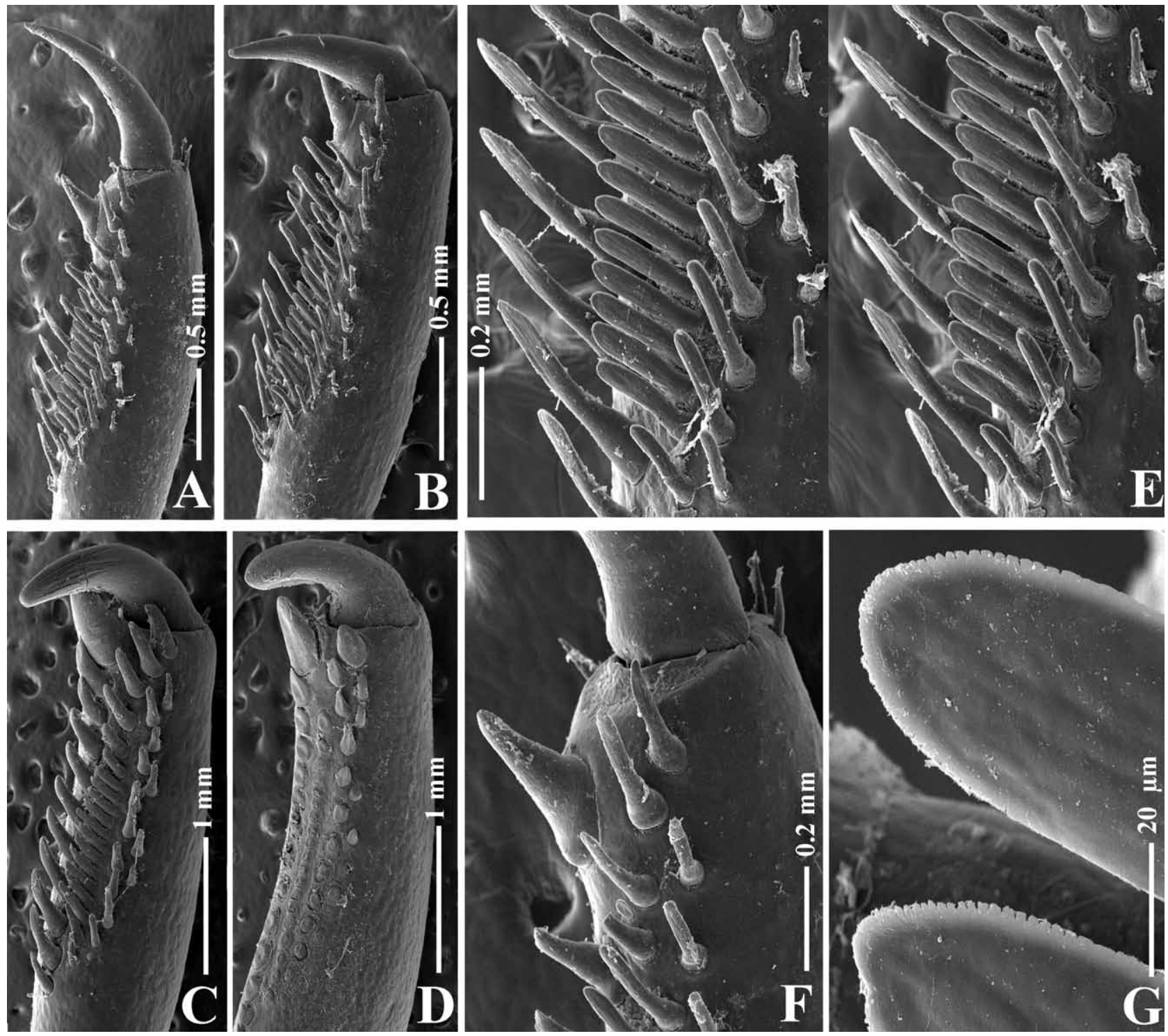

FIG. 7. - Colossendeis australis Hodgson, 1907. SEM photographs: A-D, terminal oviger segment, showing progressive eroded estate in four different specimens increasing in size (MNA: 1080, MNA: 1080, MNA: 1081, BEIM: CRP-11, respectively); E, detail from A, showing rows of compound spines, stereo pair; F, detail from A, showing a distalmost compound spine enlarged forming subchela, note basal articulation; $\mathrm{G}$, distal part of a compound spine showing pectinate border.

Cape Adare, Victoria Land, Ross Sea, Antarctica, $71^{\circ} 15.5^{\prime} \mathrm{S}$ $170^{\circ} 41.9^{\prime} \mathrm{E}, 15 \mathrm{Feb} 2004$, Agassiz trawl, 119-120 m depth, one female.

Description. Size moderately large for the genus, up to $210 \mathrm{~mm}$ leg span in the examined material.

Proboscis cylindrical and rounded distally, with minute setae irregularly distributed, bent downwards, widely inflated from narrow base, about 1.56 times (average based on four adults, range 1.5-1.6) the length of trunk.

Trunk without segmental suture-line traces, with lateral processes well separated, at least half of process diameter (more accentuated in juveniles); dorsal surface and processes with setules irregularly distributed.
Abdomen as continuation of dorsal trunk profile, with setules.

Ocular tubercle as a broad cone, distinct four eyes, anterior pair slightly larger than posterior pair.

Palps 10-segmented, slender, longer than proboscis, with many short sharp setae. Seventh segment larger than any of the three distal ones, 1.66 times (average based on four adults, range 1.5-1.9) length of sixth. Eight and ninth segments subequal, tenth segment about 1.4 (average based on four adults, range 1.30-1.56) the length of ninth.

Ovigers 10-segmented and conventional, strigilis well developed, terminal segment with 4 rows of compound spines, elongated and flat, with pectinate 
borders (see Fig. 7). Most distal compound spine enlarged to form subchela, articulation of this spine clearly distinguishable (see Fig. 7F). Terminal claw slender, slightly curved, about 0.32 times (average based on four adults, range $0.23-0.48$ ) distal segment length.

Legs slender, femur and tibiae subequal, segment covered by setules, 3 major segments armed with 6 rows of short setae. Tarsus and propodus with a distinct ventral row of spines. Tarsus about 1.35 times (average based on four adults, range 1.14-1.6) propodus length. Claw slightly curved, about 0.45 times propodal length (average based on four adults, range $0.43-0.51)$.

Measurements (in mm), based on the larger specimen in the collection MNA (1081). Length of trunk (tip of cephalic segment to tip of fourth lateral processes): 17. Width of trunk across first lateral processes: 9.5. Length of proboscis: 27. Length of abdomen: 4.6. Length of palp: 36.7 ; articles of palp length (1 to 10): 0.8-0.8-15-1.6-8.1-1.6-3.1-1.8-1.72.2. Length of third leg: 96.5 ; articles of leg 3 length: coxa 1 (2.7), coxa 2 (3.4), coxa 3 (3), femur (23), tibia 1 (23), tibia 2 (23), tarsus (9), propodus (6.5), claw (2.9). Length of oviger: 48; articles of oviger length $\left(1^{\text {st }}\right.$ to $\left.10^{\text {th }}\right): 1-1-1.4-14-3.5-11-3.3-3-$ 3.3-3.4, ovigeral claw 1.6.

Geographical and bathymetric distribution. According to previous records (see Child, 1995b for a complete list of references), this species is present in Antarctic and sub-Antarctic waters with a circumpolar distribution and some sites in the southern Pacific and southern Atlantic basins. The bathymetric distribution of Colossendeis australis has a wide range, 143-3931 $\mathrm{m}$ in depth.

Remarks. The material examined for this study agrees in general aspects with the original descriptions given by Hodgson (1907) and subsequent ones by Bouvier (1913), Calman (1915) and Fry and Hedgpeth (1969). In the most recent report on Antarctic Colossendeis species, Child (1995b) briefly diagnosed a set of characters for this species, including the subequal distal three palp segments. In our material, and previously cited literature, the eighth and ninth palp segments are reported as subequal, but the tenth segment is slightly larger (see above description for average and ratio in the examined material).

Calman pointed out some differences in the development of the distal enlarged spine forming subchela between his specimen and the type examined by Hodgson. According to the present study, these differences are simply due to the erosion of the compound spines of the strigilis, probably due to the cleaning function of these appendages.

\section{Colossendeis wilsoni Calman, 1915} (Figs. 8-9)

Material examined. MNA (1082), Italica XIX cruise, Cape Hallett, Victoria Land, Ross Sea, Antarctica, $72^{\circ} 17.9^{\prime} \mathrm{S} 170^{\circ} 26.2^{\prime} \mathrm{E}, 12 \mathrm{Feb}$ 2004, Agassiz trawl, 218-228 m depth, one juvenile. BEIM (CRP12), Italica XIX cruise, Cape Hallett, Victoria Land, Ross Sea, Antarctica, $72^{\circ} 17.4^{\prime} \mathrm{S} 170^{\circ} 26.4^{\prime} \mathrm{E}, 17 \mathrm{Feb} 2006$, Agassiz trawl, 205-258 m depth, one juvenile. MNA (1083), Italica XIX cruise, Cape Hallett, Victoria Land, Ross Sea, Antarctica, $72^{\circ} 17.4^{\prime}$ 'S $170^{\circ} 26.4^{\prime} \mathrm{E}, 17 \mathrm{Feb} 2006$, Agassiz trawl, 205-258 m depth, one female.

Description. Size moderate for the genus, up to $145 \mathrm{~mm}$ leg span in the examined material.

Proboscis cylindrical and rounded distally, smooth, inclined downwards, about 1.3 times (1.45 and 1.6 times in the juvenile specimens examined) the length of trunk.

Trunk with intersegmental suture-line traces, with lateral processes separated by narrow distance, first and second processes practically touching, while second to third and third to fourth spaces about 0.25 times process diameter; dorsal surface and processes smooth.

Abdomen curved downwards, as continuation of dorsal trunk profile, smooth.

Ocular tubercle as a low cone with narrowing but not pointed apex and wide base, juvenile specimens with a taller cone. Four distinct eyes, anterior pair slightly larger than or similar to posterior pair.

Palps 9-segmented, slender, longer than proboscis, with minute setae on distal segments. Seventh segment larger than two distal ones, about 1.3 times (1.1 and 1.5 in the juvenile specimens examined) length of sixth, and ninth segment subequal to eighth.

Ovigers 10-segmented and conventional, strigilis well developed, distal segment with 3-4 rows of compound spines, short, robust, with distal part concave to spoon-shaped and smooth borders (see Fig. 9). Claw elongated, slender, curved, with grooves on its distal part, about 0.8 times length of terminal segment $(0.8$ and 0.9 in the juvenile specimens examined).

Legs slender, femur and first tibia subequal, second tibia longer. Distal part of the second tibia, tarsus and propodus with a distinct ventral row of 

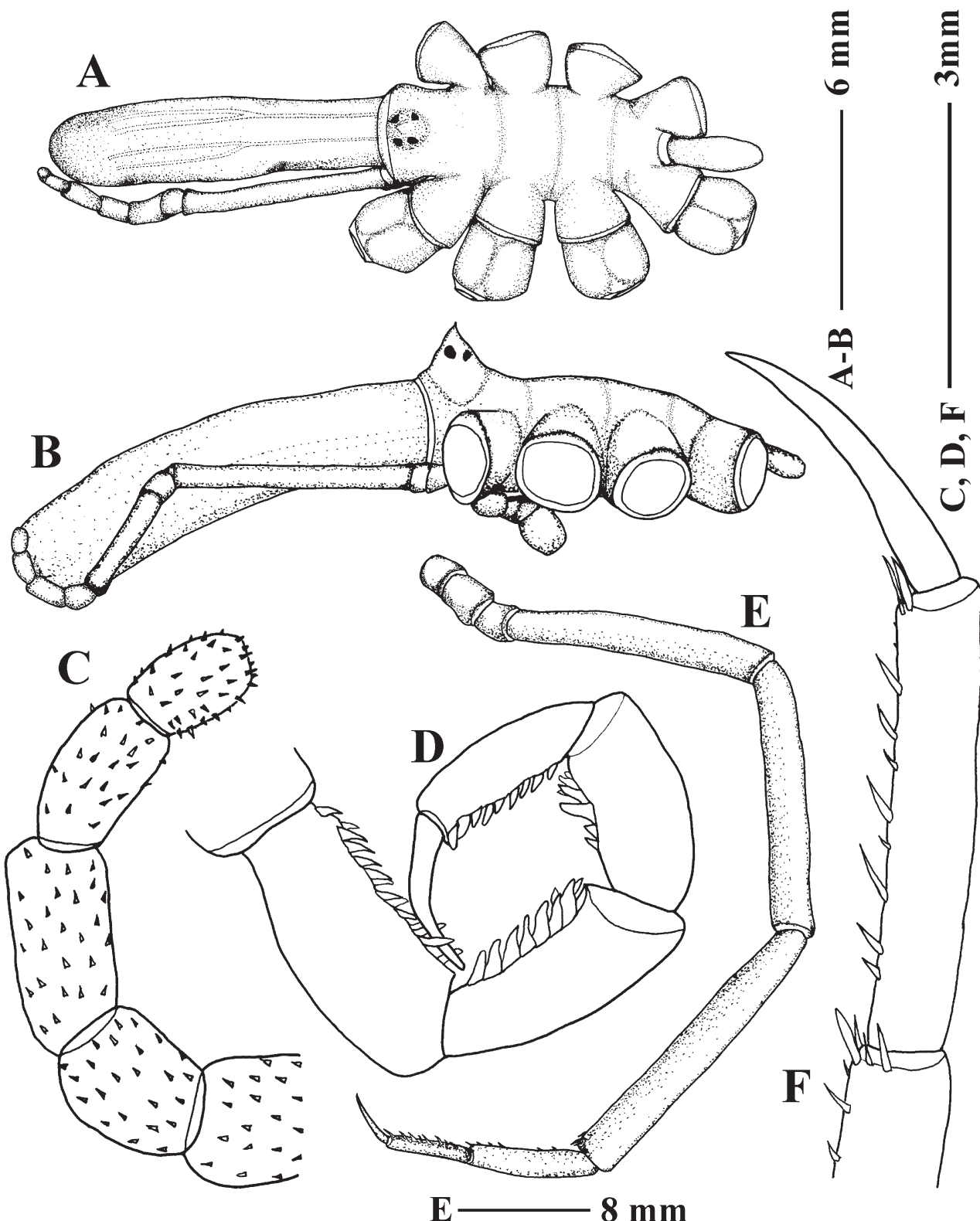

FIG. 8. - Colossendeis wilsoni Calman, 1915. (MNA: 1083): A, dorsal view of body; B, lateral view of body; C, distal segments of palp; D, strigilis; E, third leg of right side; F, distal leg segments.

spines. Tarsus about 1.25 times propodus length (1.27 and 1.35 in the juvenile specimens). Claw slightly curved, about 0.7 times $(0.5$ and 0.6 times in the juvenile specimens examined) propodal length.

Measurements (in mm), based on the larger specimen in the collection MNA (1083). Length of trunk (tip of cephalic segment to tip of fourth lateral processes): 7.8. Width of trunk across first lateral processes: 5.4. Length of proboscis: 10.1. Length of abdomen: 3.4 . Length of palp: 15.8; articles of palp length (1 to 9): 0.7-0.4-6.4-0.7-3.2-1.1-1.4-1-0.9. Length of third leg: 70.3; articles of leg 3 length: coxa 1 (1.9), coxa 2 (1.6), coxa 3 (1.6), femur (15), tibia 1 (16), tibia 2 (19), tarsus (6.5), propodus (5.2), claw (3.5). Length of oviger: 32.6; articles of oviger length $\left(1^{\text {st }}\right.$ to $\left.10^{\text {th }}\right): 0.9-0.8-1-8 \cdot 1-2.7-7.9-2.9-2.2-2-$ 1.8 , ovigeral claw 1.4 .

Geographical and bathymetric distribution. This species has been reported from Antarctic areas at shallower depths than other Colossendeis species studied in this contribution (from about 100 to 801 $\mathrm{m})$, with a known geographical distribution from Scotia Sea and South Shetland Islands to Ross Sea 

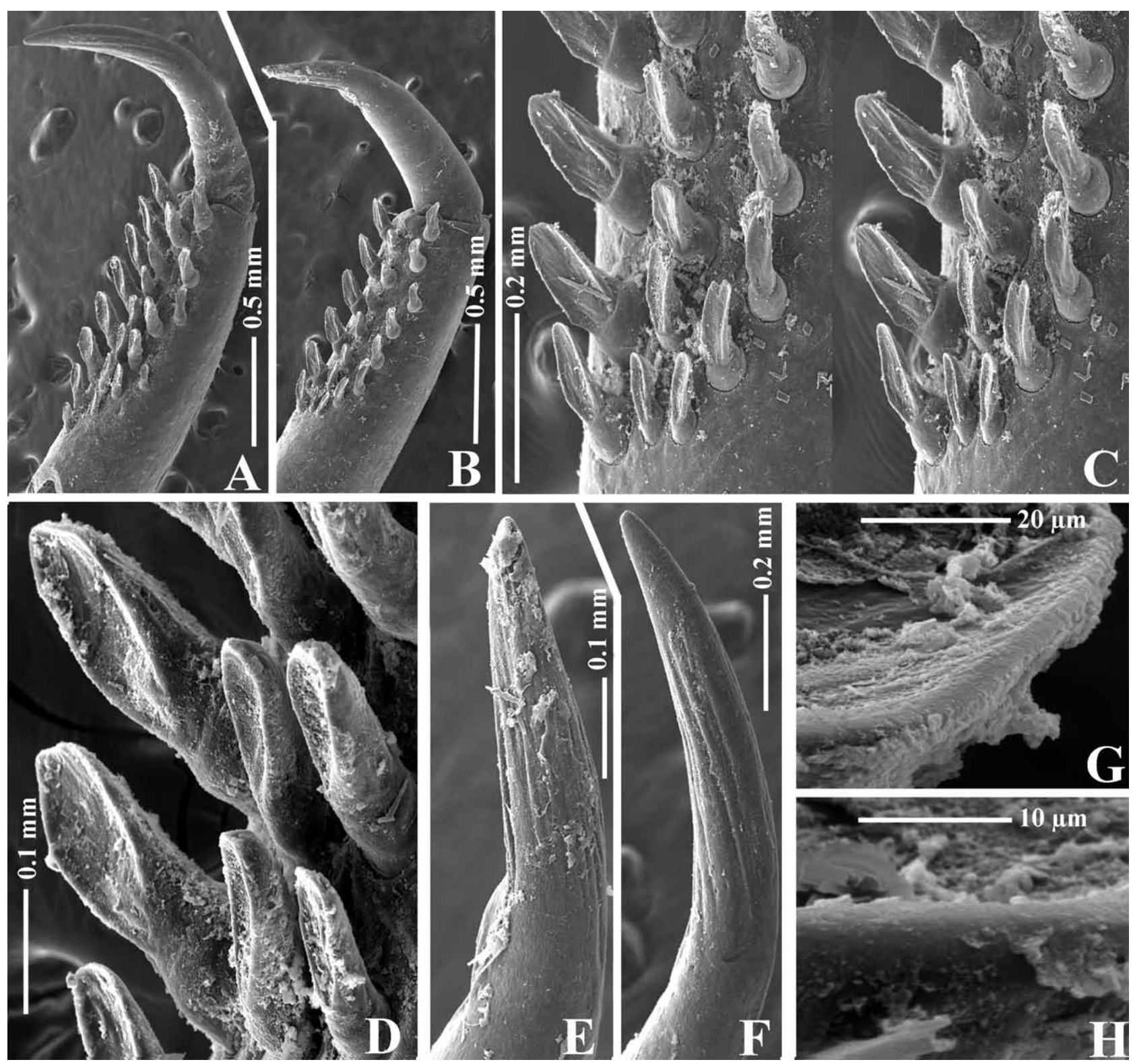

FIG. 9. - Colossendeis wilsoni Calman, 1915. SEM photographs: A-B, terminal oviger segment (MNA: 1082, MNA: 1083, respectively); C, detail from B, showing rows of compound spines, stereo pair; D, detail from A, showing a set of compound spines; E-F, detail from A and $\mathrm{B}$, showing distal portion of terminal claw; G-H, details from A and B, larger compound spines showing smooth borders.

and Adelie Land (see Fry and Hedgpeth, 1969 and Child, 1995b for a complete list of records).

Remarks. Colossendeis wilsoni was described by Calman (1915) as a robust species, with "legs short and stout, third pair not quite seven times as long as trunk", although this observation was based on a single female. Fry and Hedgpeth (1969) added more data to our knowledge of the variability in this species, based on the examination of seven adults (although in the "Examined material" only five new specimens are cited). Finally, Child (1995) studied 22 individuals from USARP cruises, recognising that all known specimens of $C$. wilsoni contributed little to understanding the true variability of this species. In the present report, 3 specimens (1 adult plus 2 juveniles) are examined.

This species has a robust appearance due to the crowded lateral processes and relatively short legs. Calman's figures and descrition indicated that the lateral processes are touching (the third and fourth lateral processes just slightly separated). According to Fry and Hedgpeth they are close to one another but not so crowded. Child indicated that the lateral processes were "closely crowded". Our observations partially agree with Calman's and Fry and 
Hedgpeth's notes, where the first and second lateral processes are touching, while the second and third, and third and fourth are separated by about 0.2 times their maximum diameter. The relative proportion between the lengths of the third leg and trunk was a little less than 7 for Calman, 6.51 to 7.83 for Fry and Hedgpeth, and 9 based on the specimens collected for this study. The relatively longer leg in our specimens also affects the relation in length between leg and proboscis, ranging from 5.22 to 6.48 for Fry and Hedgpeth, but 0.78 in our specimens.

There are also differences in the relative length of tarsus and propodus in both the published descriptions and the present material. Calman found "tarsus a little shorter than propodus", with a tarsus:propodus ratio of 0.87 for the holotype, the single specimen examined by this author. Fry and Hedgpeth included in their report the length variation ranges for tarsus (8.5-9.94) and propodus (7.05-9.94). Finally, Child, examining 22 specimens, just indicated that the tarsus and propodus are subequal, without any indication of ranges or averages. In our specimens, the tarsus-propodus ratio was 1.25 for the adult individual and about 1.3 in the juveniles. Thus, this character should be used with caution until the variation range is defined with more certainty, especially as few specimens have been examined.

Colossendeis lilliei Calman, 1915

(Figs. 10-11)

Material examined. MNA (1084), Italica XIX cruise, Coulman Island, Victoria land, Ross Sea, Antarctica, $73^{\circ} 24.5^{\prime} \mathrm{S} 170^{\circ} 23.2^{\prime} \mathrm{E}$, $19 \mathrm{Feb} 2004$, Agassiz trawl, 474-478 m depth, one male. BEIM (CRP-13), Italica XIX cruise, Cape Hallett, Victoria Land, Ross Sea, Antarctica, $72^{\circ} 17.9^{\prime} \mathrm{S} 170^{\circ} 26.2^{\prime} \mathrm{E}, 12 \mathrm{Feb} 2004$, Agassiz trawl, 218-228 m depth, one male.

Description. Size moderate for the genus, up to $124 \mathrm{~mm}$ leg span in the examined material.

Proboscis cylindrical and truncated distally, smooth, inclined downwards, slightly inflated from base, 1.2 to 1.4 times the length of trunk.

Trunk with intersegmental suture-line traces, with lateral processes separated, about 0.25 times process diameter, the first and second closest; dorsal surface and processes smooth.

Abdomen as continuation of the trunk profile, without setules.

Ocular tubercle as a broad cone, blunt, four distinct eyes, anterior pair slightly larger than posterior pair.
Palps 10-segmented, slender, longer than proboscis, with many short sharp setae on distal segments. Seventh segment larger than any of the three distal ones, about 1.2 times length of sixth. Eight and ninth segments subequal (0.8 to 1$)$, tenth segment much shorter than the two previous ones.

Ovigers 10-segmented and conventional, strigilis well developed, distal segment with 3-4 rows of compound spines, short, robust, with distal part concave spoon-shaped and smooth borders (see Fig. 11). Terminal claw slender, slightly curved, smooth surface, about 0.8 times the length of the segment.

Legs slender, femur and first tibia subequal, second tibia longer, 3 distal segments with short spines, not clearly arranged in rows. Tarsus and propodus subequal in length. Claw slightly curved, about 0.7 times propodal length (based on two specimens).

Measurements (in mm), based on the larger specimen in the collection MNA (1084). Length of trunk (tip of cephalic segment to tip of fourth lateral processes): 7.8. Width of trunk across first lateral processes: 5.1. Length of proboscis: 9. Length of abdomen: 2.7. Length of palp: 13.8; articles of palp length (1 to 10): 0.6-0.5-4.7-0.7-2.7-1.1-1.3-1-0.80.7 . Length of third leg: 52.7 ; articles of leg 3 length: coxa 1 (1.5), coxa 2 (1.9), coxa 3 (1.6), femur (10.4), tibia 1 (10.5), tibia 2 (14), tarsus (5), propodus (4.5), claw (3.3). Length of oviger: 26.8; articles of oviger length $\left(1^{\text {st }}\right.$ to $\left.10^{\text {th }}\right)$ : $1.1-1-1.3-6.5-$ 2.1-6-2.1-1.7-1.7-1.4, ovigeral claw 0.9.

Geographical and bathymetric distribution. According to Fry and Hedpeth (1969), this is an Antarctic species with a circumpolar distribution in relatively shallow depths (in comparison with other Colossendeis species), between 110 and 1119 m. As Child (1995b) considered this species to be a junior synonym of $C$. robusta, it is difficult to know the possible changes to the known bathymetric and geographical distribution without a reexamination of USARP material.

Remarks. Colossendeis lilliei was described by Calman (1915) based on 3 specimens collected in McMurdo Sound. At that time, the author distinguished $C$. lilliei from $C$. robusta by "the lateral processes much closer together, the proboscis longer than the trunk, and the femur distinctly shorter than the second tibia".

Gordon (1938) reported five additional specimens from Queen Mary Land (Davis Sea, 65'5'S 
96을), differentiating (in key) C. glacialis (including $C$. gracilipes) from $C$. robusta and $C$. lilliei by a femur longer than second tibia, and the two later species by a wider separation between lateral processes in $C$. robusta than in $C$. lilliei. Some years later (Gordon, 1944) cited eleven specimens from Enderby to McRobertson Lands (65⒋ $48^{\circ} \mathrm{S} 53^{\circ} 16^{\prime} \mathrm{E}$; $66^{\circ} 48^{\prime} \mathrm{S} 71^{\circ} 42^{\prime} \mathrm{E}$; and $\left.66^{\circ} 45^{\prime} \mathrm{S} 62^{\circ} 3^{\prime} \mathrm{E}\right)$, without additional comments or descriptions.

Fry and Hedgpeth (1969) added 25 additional specimens attributable to Calman's species.
Although these authors did not include a detailed list of diagnostic characters for the species or discuss the examined material, they provided a set of concise details and size ranges that agree with the original description. Some of these characters are noteworthy (the authors only included the ranges, not averages or deviations): 1) tenth palp segment is shorter than eight and ninth, 2) second tibia is the longer segment, 3) lateral processes separated by less (about 0.25) than their own diameter, and 4) intersegmental suture lines visible.

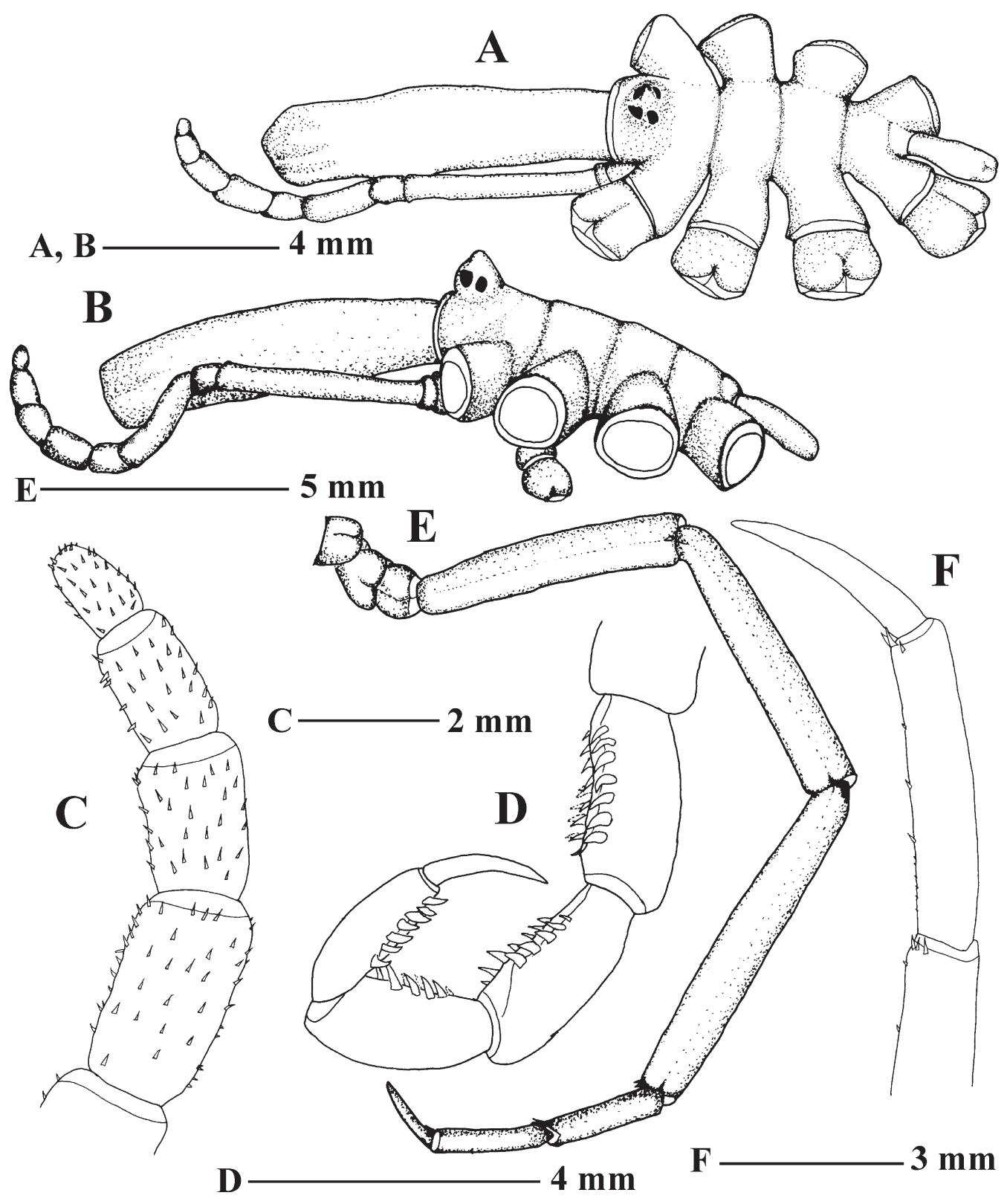

FIG. 10. - Colossendeis lilliei Calman, 1915. (BEIM: CRP-13): A, dorsal view of body; B, lateral view of body; C, distal segments of palp; $\mathrm{D}$, strigilis; E, third leg of right side; $\mathrm{F}$, distal leg segments. 


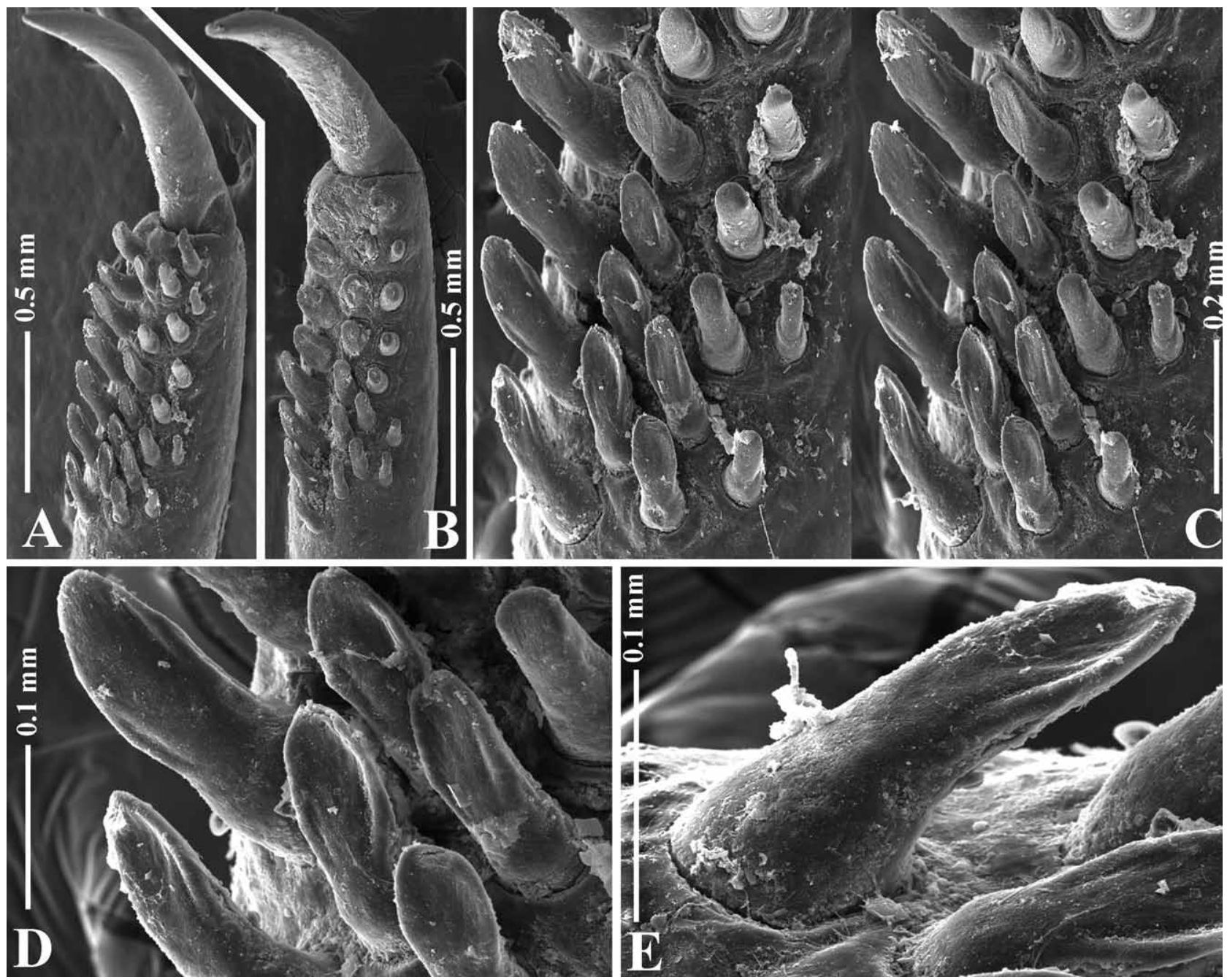

FIG. 11. - Colossendeis lilliei Calman, 1915. SEM photographs: A-B, terminal oviger segment (BEIM: CRP-13, MNA: 1084, respectively); C, detail from A, showing rows of compound spines, stereo pair; D-E, details from A, showing a set of compound spines, note smooth borders.

In spite of all previous records, Child (1995b) considered $C$. lilliei to be a junior synonym of $C$. robusta, with the same criteria used for $C$. glacialis and $C$. gracilipes (see above remarks for $C$. glacialis). However, other characters such as the presence/absence of intersegmental sutures lines, the separation of the lateral processes, the relative length of the tenth palp segment and preceding ones, and the comparison of the variability in the femur/second tibia proportions can be considered useful for separating $C$. lilliei from $C$. glacialis and C. robusta.

The material here examined from Victoria Land agrees in general with Calman's and Fry and Hedgpeth's material and comments. Although the high variability of $C$. robusta in the femur:second tibia length ratio was used by Child (1995b) to propose the synonymy of $C$. lilliei, if we plot our spec- imens and Calman's specimens on the graph provided by Fry and Hedgpeth (1969: Fig. 30), all adult specimens of $C$. lilliei are located in the square delimited by the following data: femur:second tibia ratio (0.89-0.74) and leg length (43.1-64.5 mm), whereas adult specimens of $C$. robusta (including also some specimens of $C$. glacialis, see Free and Hedgpeth, 1969: Fig. 30) are plotted on higher ratios, having longer legs. Colossendeis lilliei data are close to a juvenile specimen of $C$. robusta, so more data based on juvenile and adult specimens are needed to better define the variability of these relations in C. lilliei. However, this evidence indicates that these features could be used in future contributions in the separation of the two Colossendeis species.

Additionally, the detailed examination using SEM of the terminal segment of $C$. glacialis and $C$. 
lilliei in this contribution clearly shows that the two species should be maintained separate (see comparatively Figs 5 and 11). A similar study in C.robusta is desirable to compare it to previously synonymised species.

Colossendeis scotti Calman, 1915

(Figs. 12-13)

Material examined. MNA (1085), Italica XIX cruise, Cape Hallett, Victoria Land, Ross Sea, Antarctica, $72^{\circ} 17.5^{\prime} \mathrm{S} 170^{\circ} 10.6^{\prime} \mathrm{E}, 17 \mathrm{Feb}$ 2006, fishing bottom net (tramell), $403 \mathrm{~m}$ depth, one female. BEIM (CRP-14), Italica XIX cruise, Cape Hallett, Victoria Land, Ross Sea, Antarctica, $72^{\circ} 17.1^{\prime} \mathrm{S} 170^{\circ} 14.0$ 'E, 16 Feb 2006, Agassiz trawl, 196-202 m depth, one male.
Description. Size moderate to large for the genus, up to $280 \mathrm{~mm}$ leg span in the examined material.

Proboscis cylindrical and rounded distally, with setules irregularly distributed, bent downwards, widely inflated at mid length from narrow base, about twice the length of trunk.

Trunk without intersegmental suture-line traces, with lateral processes crowded, nearly in contact with each other; dorsal surface and processes with setules irregularly distributed.

Abdomen curved downwards, as continuation of the trunk profile, with setules.

Ocular tubercle broad and rounded, four distinct

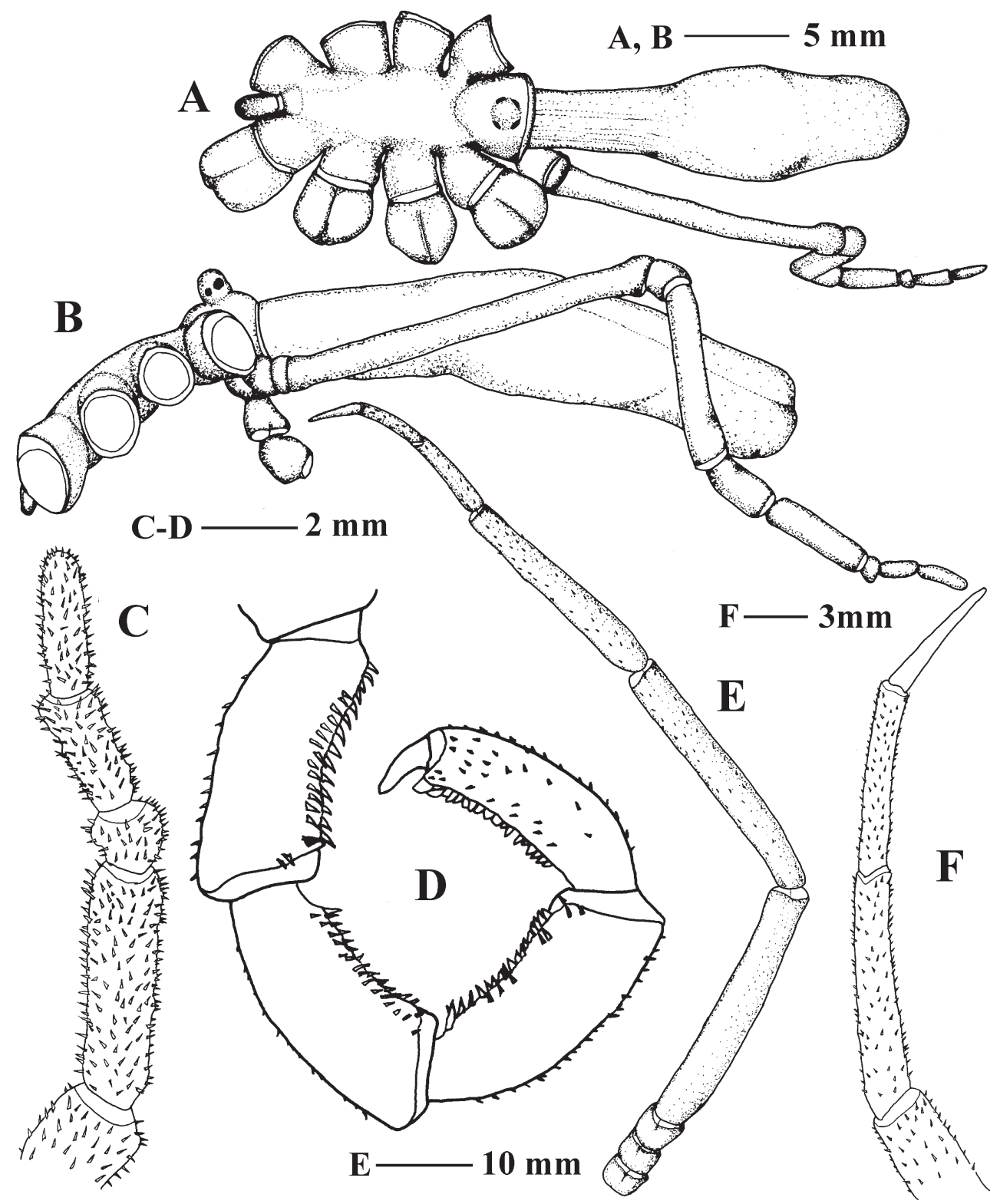

FIG. 12. - Colossendeis scotti Calman, 1915. (MNA: 1085): A, dorsal view of body; B, lateral view of body; C, distal segments of palp; D, strigilis; E, third leg of right side; F, distal leg segments. 

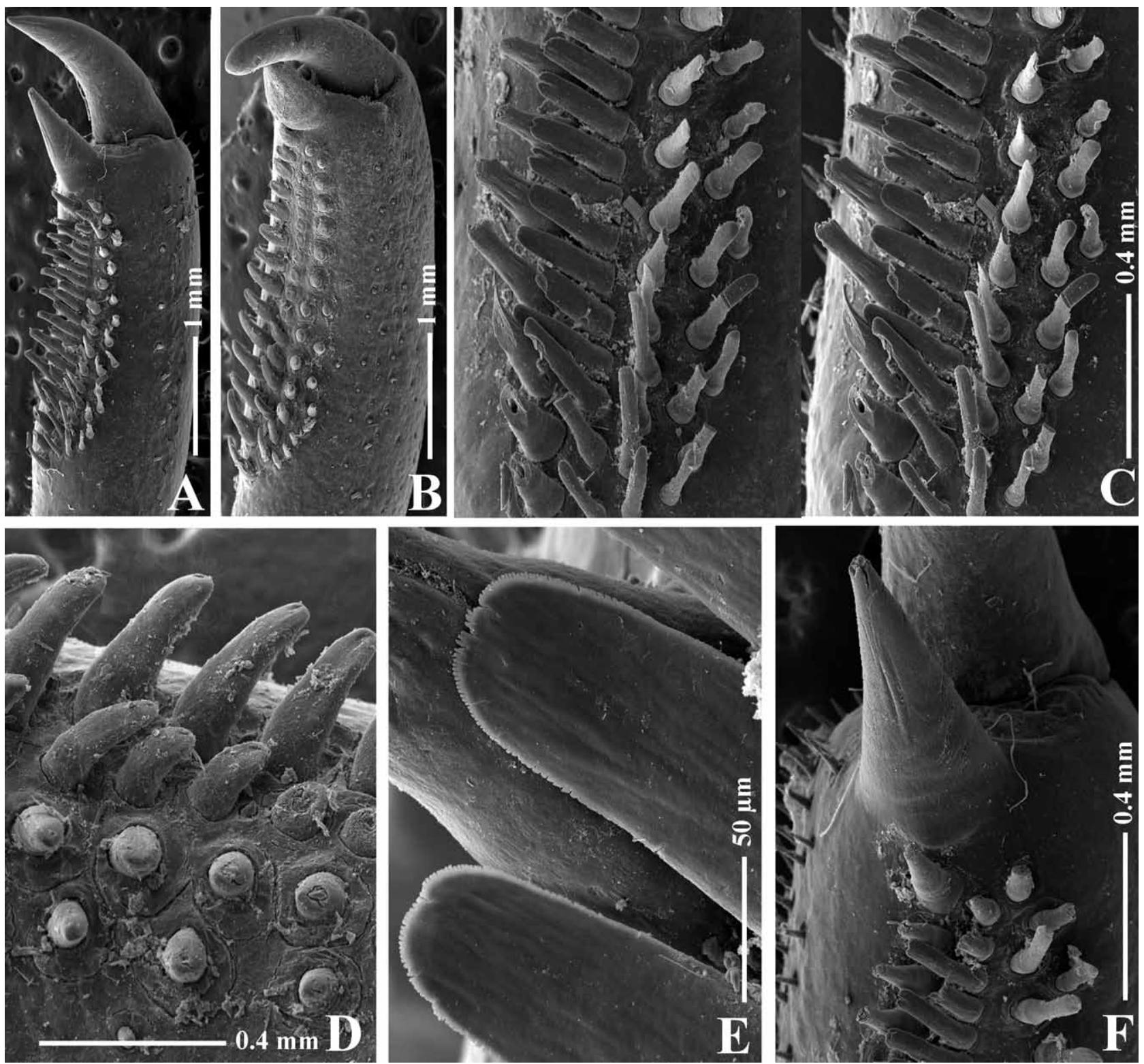

FIG. 13. - Colossendeis scotti Calman, 1915. SEM photographs: A-B, terminal oviger segment (BEIM: CRP-14, MNA: 1085, respectively); $\mathrm{C}$, detail from A, showing rows of compound spines, stereo pair; D, detail from B, showing a set of compound spines, smaller ones completely eroded; E, detail of medium-sized compound spines in A, note pectinate borders; F, detail of distalmost compound spine forming subchela in A, note its complete fusion with the segment.

eyes, anterior pair larger and slightly more distally placed than posterior pair.

Palps 10-segmented, slender, longer than proboscis, with many short sharp setae, more dense in the last six segments. Seventh segment larger than any of the three distal ones, about 1.5 length of sixth. Eighth segment distinctly shorter than distal ones, tenth segment slightly longer than ninth (1.3 to 1.5 times in the examined material).

Ovigers 10-segmented and conventional, strigilis well developed, terminal segment with 4-5 rows of compound spines, elongated and flat, with pectinate margins (see Fig. 13). Most distal compound spine on last segment enlarged to form subchela, articulation of this spine indistinguishable, completely fused to the segment (see Fig. 13F). Subchela isolated from the field of remaining compound spines. Terminal claw robust, slightly curved, pointed distally (rounded in eroded ones), about 0.3 times the length of the terminal segment.

Legs slender, femur, first tibia and second tibia progressively decreasing in length, covered by setules, irregularly distributed. Tarsus about 1.2 times propodus length. Claw nearly straight, about 
0.8 times (average based on two specimens, range 0.7 to 0.9 ) propodal length.

Measurements (in mm), based on the larger specimen in the collection MNA (1085). Length of trunk (tip of cephalic segment to tip of fourth lateral processes): 16. Width of trunk across first lateral processes: 11. Length of proboscis: 33. Length of abdomen: 6. Length of palp: 50.4; articles of palp length (1 to 10): 1.8-1.2-18-2.4-10.8-3.8-5.4-1.42.2-3.4. Length of third leg: 132.6; articles of leg 3 length: coxa 1 (3.8), coxa 2 (3.8), coxa 3 (4), femur (34), tibia 1 (32), tibia 2 (28), tarsus (11), propodus (9), claw (6). Length of oviger: 73.2; articles of oviger length ( $1^{\text {st }}$ to $\left.10^{\text {th }}\right): 2-1.5-3-17-8-18-5.3-5.3-$ 5.5-4.1, ovigeral claw 1.1.

Geographical and bathymetric distribution. Colossendeis scotti is an Antarctic species reported from the Ross and Weddell Seas, as well as the South Shetland Islands, South Sandwich Islands, and South Georgia, in relatively shallow waters 35-265 $\mathrm{m}$ in depth (see Child, 1995b for complete references). The present contribution modifies the depth record of this species moderately, up to $403 \mathrm{~m}$.

Remarks. Adult specimens of Colossendeis scot$t i$ are easily recognisable by their crowded lateral processes (touching to very slightly separated). However, this character could not be used in juvenile individuals, where they are slightly to widely separated (see Child, 1995b: 92). Other differences between adults and juveniles are the relative length of the tarsus and propodus (adult: length of thetarsus $>$ length of the propodus), and the shape of the ocular tubercle (adult: low with rounded apex; juvenile: taller cone).

The subchelate oviger, a distinctly short eighth palp segment, and the crowded lateral processes form the set of characters used to differentiate adult individuals of Colossendeis scot$t i$ from its austral congeners. There are only four austral species of Colossendeis with subchelate ovigers: C. tortipalpis, C. longirostris, C. australis and $C$. scotti. The former two are easily distinguishable by the anaxial articulation of the eighth and ninth palp segment, while in the two latter species this articulation is synaxial. Adult C. scotti differs from C. australis by its longer proboscis, crowded lateral process and shorter eighth palp segment.

\section{DISCUSSION}

\section{Remarks on palp and oviger segmentation in the genus Colossendeis}

The discussion about the 9- or 10-segmented nature of the palp in Colossendeis was already present in papers in the late 19th century. Wilson (1881), Hoek (1881), and Hodgson (1907) supported a 10segmented condition, while Bouvier (1913) and Calman (1915) considered the palps to be 9-segmented. In subsequent papers, a 9-segmented palp was accepted not only in partial revisions of fauna from different areas (see Gordon, 1932, 1938, 1944; and Fry and Hedgpeth, 1969), but also in general works, such as Arnaud and Bamber (1987).

According to Child (1995b), two short basal palp segments are present in Colossendeis species; although the suture line between the lateral extension of the cephalic segment and the first palp segment is not always clearly marked, close examination almost always reveals a separation line. This consideration (here adopted) leads to the conclusion that there is a 10-segmented palp in most Colossendeis species (9-segmented in C. wilsoni).

The number of segments of ovigers is also controversial. A suture line is present between the cephalic segment and the here-called basal element (for other authors an oviger-bearing process). If this basal element is actually the true first segment, this makes the total number of short oviger basal segments four, and the total number of segments in this appendage eleven (Fig. 14A). This basal element shows a ventral ornamentation similar to that present in the following oviger segments (Fig. 14B). This situation differs clearly from the lateral processes of the trunk, which do not show any segmentation line or articulation (see Fig. 14E). Based on observations of our material, we consider Colossendeis ovigers to be probably 11-segmented, and not 10-segmented as described in previous literature, at least for the Colossendeis material examined in this study.

Other than a footnote provided by Calman (1915: 10) about segmentation of the basal part of the ovigers, nothing is mentioned about its possible 11segmented condition. As far as the authors are aware, the only record of 11-segmented ovigers in Colossendeis is that of Wilson (1881: 242) as "Accessory legs 11-(10?) jointed". In this case, the author considered the terminal claw as a possible 

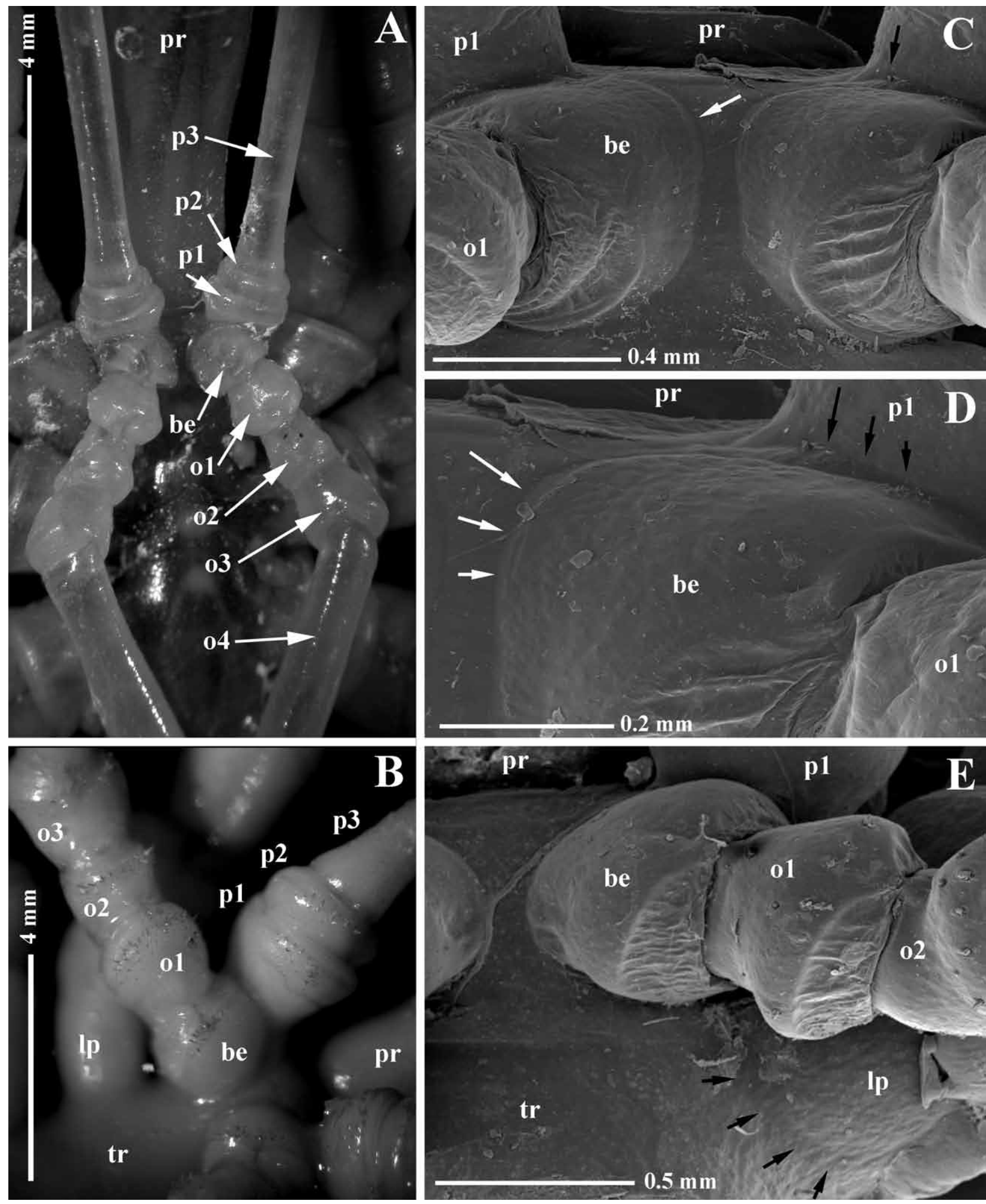

FIG. 14. - Ovigers from Colossendeis species. A, Colossendeis wilsoni (MNA: 1083), ventral view, showing basal parts of palps and ovigers; B, Colossendeis scotti (BEIM: CRP-14), basal parts of right palp and oviger; C, Colossendeis megalonyx (BEIM: CRP-7), ventral view, basal parts of palps and ovigers (white arrow indicates limit between cephalic area and basal oviger element, black arrow indicates limit between cephalic area and first palp segment); D, detail from C, basal parts of left palp and oviger (white arrows indicate limit between cephalic area and basal oviger element, black arrows indicate limit between cephalic area and first palp segment); E, Colossendeis glacialis (BEIM: CRP8), basal parts of left oviger and first left lateral process of the trunk (black arrows indicate the limit between central trunk part and lateral process). Abbreviations: be, basal element, o1-o4, first to fourth oviger segment; p1-p3, first to third palp segments; lp, lateral processe; pr, proboscis; tr, trunk. 
eleventh segment (see the description of C.macerri$m a$ on page 246), but this claw is considered by Stock (1994) to be a transformed spine. According to recent literature on the biology and phylogeny of Pycnogonida (Arnaud and Bamber, 1987; Munilla, 1999; Arango, 2002, 2003), a 10-segmented status is considered a less derived condition if the 11-segmented oviger of the Devonian fossil Palaeoisopus problematicus Broili is the plesiomorphic state in the group (Stock, 1994; Arango, 2002).

As palps and ovigers show a similar situation in their respective basal parts (see Fig. 14C, D), if a 10segmented palp is considered, a 11-segmented oviger should not be rejected, because the two considerations seem to be linked. A more detailed study of this will be carried out in the near future, including histological and SEM preparations, especially covering a larger number of specimens and species than that available for the present study. However, until that moment, to avoid incoherences with the most recent published literature (Child, 1995b), in this paper we have considered palps and ovigers to be 10-segmented (with the exception of th e9-segmented palp in $C$. wilsoni), awaiting further studies.

\section{Remarks on the taxonomic utility of some characters from the strigilis in the genus Colossendeis}

In the genus Colossendeis the presence of several rows of compound spines can be observed in the four terminal segments of the ovigers (strigilis according to Child, 1979). These fields of compound spines are shared with other Colossendeidae genera like Dodecolopoda and Decolopoda (see Fry and Hedgpeth, 1969).

The presence of compound spines in the terminal oviger segments of Colossendeis has already been noted and discussed by several authors. Some of them illustrated these spines (see for example Hoek, 1881: plate IX, Fig. 5 for C. robusta, C. megalonyx, and $C$. gracilis; and Hodgson, 1907: plate X, for $C$. australis), and others also commented on the number of rows in which these are arranged (see Calman, 1915: 19, 5 rows for C. wilsoni; Hoek, 1881: plate X, Fig. 1: up to 12 rows for $C$. gigas). The quality of the observations of the shape of these spines varied, although a general idea of spines with "finely feathered distally denticulate edges" (see Child, 1995b: 72) has been maintained. Nevertheless, the morphological possibilities of these spines are much more diverse. Fry and Hedgpeth (1969: 26) made a great effort to use the spatulate or non-spatulate condition of the terminal claw and the number of rows and shape of spines to characterise the Colossendeis species (also including a formulation). These authors considered four morphological types of oviger spines, peg, needle, spatulate, and molariform, most of them present in all species, but arranged in delimited fields in different orders of importance in the different Colossendeis species. Similar observations were made by Munilla (1991), who determined that molariform forms are originated by the use of ovigers in the cleaning task. Although the present study differs from Fry and Hedgpeth's and Munilla's conclusions in the consideration of the types and distribution of spines present in each species, we agree on the utility of these characters not only for differentiating species, but also for establishing possible relations between species or groups of species.

As stated above, the purpose of ovigers and their compound spines is related to cleaning behaviours, which lead to erosion (resulting in the molariform type of Fry and Hedgpeth, 1969) and thus reduce their utility as a source of taxonomic characters in mature (usually larger) specimens. Despite these limitations, we have examined the right terminal oviger segment of 2-5 specimens from each of the available Colossendeis species. The results of this study show a number of characters that can be used in the taxonomy of this genus.

It is highly desired to study other Colossendeidae species under SEM in order to complete (if possible) the dataset, scoring other characters, and testing with more data the potential utility of oviger characters in the internal relationship of this genus and family. However, in this paper we have not attempted to make premature speculations on phylogenetic relationships, which could well be the goal of other investigations that may be helped by techniques different from those of traditional taxonomists.

\section{ACKNOWLEDGEMENTS}

The authors would like to thank Dr. Roger Bamber (NHM, UK) for his helpful comments during the preparation of this paper, as well as referees' and editorial suggestions. We also wish to thank the officers and crew and many colleagues for their help on board during the VLT-2004 (Italica, XIX 
Spedizione) cruise. We take this opportunity to extend our thanks to the cruise leader and steering committee of the cruise, especially Riccardo Cattaneo, Maria Chiara Chiantore and Roberto Meloni, who kindly facilitated the work on board and allowed us to collaborate in this Antarctic programme. Support for this work was provided by the Spanish CICYT project CGL2004-20062-E.

\section{REFERENCES}

Arnaud, F. and R. Bamber. - 1987. The Biology of Pycnogonida Adv. Mar. Biol., 24: 1-96.

Arango, C.P. - 2002. Morphological phylogenetics of the sea spiders (Arthropoda: Pycnogonida). Org. Divers. Evol., 2: 107-125.

Arango, C.P. - 2003. Molecular approach to the phylogenetics of the sea spiders (Arthropoa: Pycnogonida) using partial sequences of nuclear ribosomal DNA. Mol. Phyl. Evol., 28: $588-600$.

Bouvier, E.L. - 1913. Pycnogonides du Pourquoi Pas? In: Calman WT (ed.), Deuxième Expédition Antarctique française (19081910), 6, pp. 1-169. Masson, Paris.

Calman, W.T. - 1915. Pycnogonida. British Antarctic (Terra Nova) Expedition, 1910. Zoology, 3(1): 1-74.

Child, C.A. - 1979. Shallow-Water Pycnogonids of the Isthmus of Panama and the Coasts of Middle America. Smithson. Contrib. Zool., 293: 1-86.

Child, C.A. - 1994a. Antarctic and Subantarctic Pycnogonida I. The Family Ammotheidae. In: S.D. Cairns (ed.), Biology of the Antarctic Seas XXIII, Antarc. Res. Ser., 63: 1-48.

Child, C.A. - 1994b. Antarctic and Subantarctic Pycnogonida II The Family Austrodecidae. In: S.D. Cairns (ed.), Biology of the Antarctic Seas XXIII, Antarc. Res. Ser., 63: 49-99.

Child, C.A. - 1995a. Antarctic and Subantarctic Pycnogonida III. The Family Nymphonidae. In: S.D. Cairns (ed.), Biology of the Antarctic Seas XXIII, Antarc. Res. Ser., 69: 1-68.

Child, C.A. - 1995b. Antarctic and Subantarctic Pycnogonida IV. The Family Colosendeidae and Rhynchothoraxidae. In: S. D. Cairns (ed.), Biology of the Antarctic Seas XXIII, Antarc. Res. Ser., 69: 69-111.

Child, C.A. - 1995c. Antarctic and Subantarctic Pycnogonida V.
The Family Pycnogonidae, Phoxilidiidae, Endeidae and Callipallenidae, including the genus Pallenopsis. In: S.D. Cairns (ed.), Biology of the Antarctic Seas XXIII, Antarc. Res. Ser., 69: 113-160.

Chimenz, C. and M.F. Gravina. - 2001. Faunistical and biological traits of some Antarctic Pycnogonida. Ital. J.Zool., 68: 335-344.

Fry, W.G. and J.W. Hedgpeth. - 1969. Pycnogonida, 1. Colossendeidae, Pycnogonidae, Endeidae, Ammotheidae. Fauna of the Ross Sea, 7. Mem. N.Z. Oceanogr. Inst., 49: 1-139.

Gordon, I. - 1932. Pycnogonida. Disc. Rep., 6: 1-138.

Gordon, I. - 1938. Pycnogonida. Sci. Rep. Australas. Antarc. Exp. Zool. Bot., 2: 1-40.

Gordon, I. - 1944. Pycnogonida. Rep. Br. Aust. N. Z. Exp.B, 5(1): $1-172$.

Hodgson, T.V.-1907. Pycnogonida. National Antarctic Expedition 1901-1904. Reports of the National Antarctic expedition of 1901-1904. Nat. Hist., 3: 1-172.

Hodgson, T.V. - 1908. The Pycnogonida of the Scottish National Antarctic Expedition. Trans. Royal Soc. Edinburgh, 46: 159-188.

Hoek, P.P.C. - 1881. Report on the Pycnogonida dredged by HMS Challenger 1873-1876. Rep. Sci. Res. Challenger, 3(10): 1-167.

Munilla, T. - 1991. Picnogónidos capturados en la Campaña “Antártica 8611". Bol. Inst. Esp. Oceanogr., 7: 3-44.

Munilla, T. - 1999. Evolución y Filogenia de los Picnogónidos. Bol. Soc. Ent. Aragonesa, 26: 273-279.

Pushkin, A.F. - 1993. The pycnogonida fauna of the South Ocean. Biological results of the soviet Antarctic expeditions. Explorations of the fauna of the seas XX(XXX): 1-397.

Stiboy-Risch, C. - 1993. Funde antarktischer und subantarktischer Pantopoden einschlie,lich Colossendeis acuta sp.n. -sowie ein Beitrag zur Artbestimmung von Colossendeis glacialis Hodgson, 1907 und Colossendeis robusta Hoek, 1881. Mitt. Hamb. Zoo.l Mus. Inst. 90: 251-264.

Stock, J.H. - 1994. Indo-West Pacific Pycnogonida collected by some major oceanographic expeditions. Beaufortia, 44(3): 17-77.

Turpaeva, E.P. - 1974. The pycnogonida of the Scotia Sea and surrounding waters. Tr. Inst. Okeanol., Akad. Nauk. SSSR 98: 277-305.

Wilson, C.B. - 1881. Report on the Pycnogonida. Reports on the results of dreging, under the Supervision of Alexander Agassiz, along the East Coast of the United States, during the Summer of 1880, by the U.S. Coast Survey Steamer "Blake". Bull. Mus. Comp. Zool. Harvard Univ., 8(12): 239-256.

Scient. ed.: P. Abelló

Received January 8, 2007. Accepted July 3, 2007.

Published online October 4, 2007. 